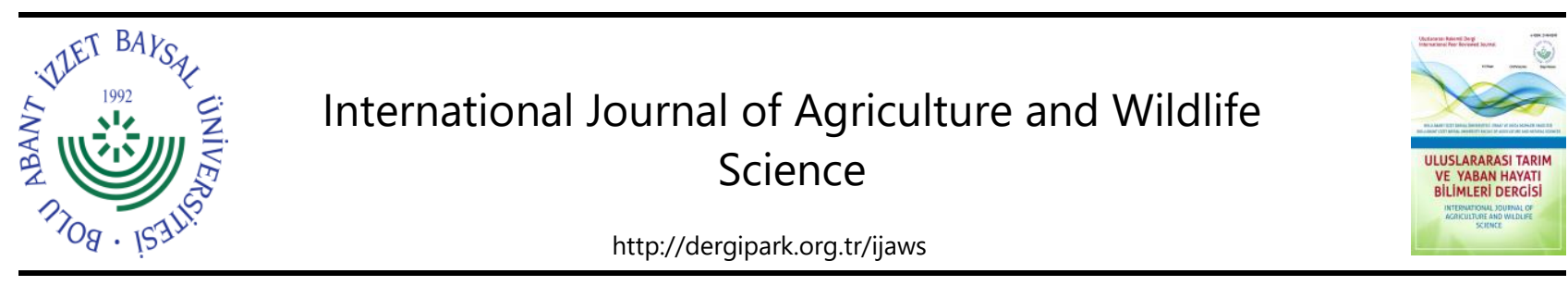

Research Article

\title{
Effects of Different Biological Fertilizers Formulated with Multiple Bacteria and Carriers in Pazar 20 Tea Clone on Leaf Enzyme Activity
}

\author{
Yaşar Ertürk ${ }^{* *}$ (D) Ramazan Çakmakçı ${ }^{2}$ (D) $\quad$ Meral Kutlu ${ }^{3}$ \\ 'Department of Horticulture, Faculty of Africulture, Ahi Evran University, Kırşehir, Turkey \\ ${ }^{2}$ Department of Crop Science, Faculty of Agriculture, Çanakkale Onsekiz Mart University, Çanakkale, Turkey \\ ${ }^{3}$ Department of Crop Science, Faculty of Agriculture, Atatürk University, Erzurum, Turkey
}

Received: 16.08.2021 Accepted: 06.11.2021

Keywords:
Camellia sinensis L, PGPR
formula, enzym activity,
carriers

*Corresponding author yasar.erturk@ahievran.edu.tr

\begin{abstract}
This study was performed on 2-year-old seedlings of the Pazar-20 tea clone pots in 20142015. Twelve different bacterial isolates (Bacillus atrophaeusRC11, Bacillus megateriumRC07, Bacillus megaterium42/4, Bacillus megaterium21/3, Pseudomonas fluorescensRC77, Pseudomonas fluorescens 8/4, Pseudomonas fluorescens8/6, Pseudomonas fluorescens9/7, Bacillus subtilisRC63, Bacillus subtilis 39/3, Bacillus subtilis36/10, Bacillus subtilisRC521), which were isolated from acidic tea soils and characterized and all laboratory tests were performed. With biological fertilizers formed by triple combinations and 7 different carrier formulations (K-tea compost, T-peat, $\mathrm{P}$-perlite, L-leonardite, Zzeolite, $\mathrm{V}$-vermiculite and $\mathrm{S}$-liquid carrier formulation) on the enzyme activities (peroxidase-POD, Polyphenol oxidase-PPO, Urease, 5-Dehydroxyshikimate reductase, Alchol dehydrogenase-ADH, Glucose 6-phosphate dehydrogenase-G6PD, 6-phosphogluconate dehydrogenase-6PGD, Glutathione reductase-GR and Glutathione S-transferase-GST) of tea leaves were determined. All bacterial formulations used in the study positively affected the enzyme activities in the tea leaves at different rates compared to the control. This activity was found to be statistically significant. Additionally, it was determined that the efficiency of the carrier was important in both years (2014-2015) statistically, liquid formula and peat carriers had the highest effect.
\end{abstract}

\section{Çoklu Bakterilerle Oluşturulmuş Farklı Biyolojik Gübre Formulasyonlarının Pazar 20 Çay Klonunda Yaprak Enzim Aktivitesine Etkileri}

Anahtar kelimeler:
Camellia sinensis L., PGPR
formülleri, enzim aktivitesi,
taşıyıcılar

taşıyıcılar Özet. Bu çalışma, 2014-2015 yıllarında potlarda, Pazar-20 çay klonuna ait 2 yaşlı fidanlarda
yürütülmüştür. Asidik çay topraklarından izole edilerek tanılanan ve karakterize edilip tüm laboratuvar
testleri yapılan, biyolojik gübre adaylarından 12 farklı bakteri izolatının (Bacillus atrophaeusRC11,
Bacillus megateriumRC07, Bacillus megaterium42/4, Bacillus megaterium21/3, Pseudomonas fluorescen
RC77, Pseudomonas fluorescens8/4, Pseudomonas fluorescens8/ 6, Pseudomonas fluorescens9/7,
Bacillus subtilisRC63, Bacillus subtilis39/3, Bacillus subtilis36/10, Bacillus subtilisRC521) üçerli
kombinasyonları ile oluşturulmuş biyolojik gübre formulasyonları ile 7 farklı taşıyıcının (K-çay
kompostu, T-torf, P-perlit, L-leonardit, Z-zeolit, V-vermikülit ve S-likit taşıyııı formulasyonu) birlikte
uygulanmalarının çay yapraklarının enzim aktivitelerine (Peroksidaz-PO, Polifenol oksidaz- PPO, Üreaz,
5-Dehidroksişikimat Redüktaz, Alkol dehidrogenaz-ADH, Glikoz 6 fosfat dehidrogenaz-G6PD, 6 Fosfo
glukonat dehidrogenaz-6PGD, Glutatyon redüktaz-GR, Glutatyon S-transferaz-GST) etkileri
belirlenmiştir. Araştırmada kullanılan tüm bakteriyel formulasyonlar, çay yaprağındaki enzim
aktivitelerini kontrole kıyasla farklı oranlarda olumlu yönde etkilemiştir. Bu etkinlik istatistiki olarak
önemli bulunmuştur. Ayrıca, yapıllan değerlendirmelerde, her iki yılda da (2014-2015) taşıyıcıların da
etkinliğinin önemli olduğu, likit formüllü taşıyıcı ile torf olarak kullanılan taşıyıcıların en yüksek etkiye
sahip oldukları belirlenmiştir. 


\section{INTRODUCTION}

Tea (Camellia sinensis L. Kuntze), which is one of the most popular beverages around the world with its characteristic aroma and flavor, is an important horticultural plant that has become widespread in subtropic and tropic fields and its leaves are used. Especially the development period, which needs a lot of nitrogen, has also caused the use of intensive inorganic fertilizers for yield increase. Fertilization (especially nitrogen) is of great importance in the development of tea leaves, which are harvested at least 3 or 4 times a year due to their herbal characteristics (Kacar, 2010). Most of the fertilizer in agricultural fields are lost due to immobilization, evaporation, and washing. Particularly, a significant part of the nitrogen applied in tea growing regions is washed away due to effective precipitation, high humidity, and sloping areas, and fertilizers pollute the surface and ground waters. Additionally, the high cost of chemical fertilizers, the deep gap between supply and demand, and their negative impact on the environment have led to the search for alternative strategies. Also, extensive use of agrochemicals to meet the global requirement of tea resulted in an alteration of the microbial community associated with the tea plants (Cernava et al., 2019).

As it is known, the soil is a perfect ecosystem where living and non-living components form a special harmony. Both It meets the structural needs of plants and provides living space for many living populations. Among these organisms, bacteria (non-pathogenic), which are highly effective in the root rhizosphere of plants, are positively affecting the growth and development through many direct and indirect mechanisms, which constitute an important part. For this reason, this type of bacteria is very commonly called plant growth-promoting rhizobacteria (PGPR) and is stated to serve as an environmentally friendly substitute for chemical fertilizers. The fact that its positive effects are valid for many plants has allowed this type of bacteria to be called biofertilizer.The direct effects of PGPRs on plant growth are the fixation of atmospheric nitrogen into the soil occurs by dissolving phosphate, potassium and iron in insoluble form in the soil and producing many phytohormones. In indirect mechanisms; It is most important to protect plants from biotic and abiotic stress factors. Moreover, hydrolytic enzyme production by PGPRs, production of polysaccharides, bioremediation of heavy metals and stimulation of induced systemic resistance (by mechanisms such as the biosynthesis of defense principle related molecules, increasing the levels of defense proteins) are critical contributions (Çakmakçı, 2019).

Biotic and abiotic stresses cause many different physiological changes in plant cells, including the production of reactive oxygen species (ROS). The accumulation of high concentrations of ROS in plant cells leads to oxidative damage and causes disruption of cellular homeostasis. Plant cells are equipped with advanced antioxidant mechanisms. Some of these include antioxidant defense enzymes such as Ascorbate peroxidase (APX), catalase $(C A T)$, peroxidase $(\mathrm{PO})$, superoxide dismutase (SOD), glutathione reductase, glutathione S-transferase, and guaiacol peroxidase. These enzymes are involved in scavenging and converting ROS into non-toxic end products, thereby protecting cells from oxidative damage. In addition, plant cells also produce various antioxidant molecules such as carotenoids and phenylpropanoids to overcome oxidative damage. Furthermore, PGPRassisted ISR prepares host plants to resist the pathogen invasion through the production of defense-related antioxidative enzymes and molecules (Saravanakumar et al., 2007; Çakmakçı et al., 2016; Bhattacharyya et al., 2020).

The first study on the rhizosphere microbiome of tea plantations in Turkey started in 2007 with a project supported by TUBITAK. It has been determined that the tea rhizosphere is composed of very different PGPR isolates that can be used as biological fertilizers in different locations, depending on different cultivar/clone characteristics (Çakmakçı et al., 2010 and 2016; Çakmakçı, 2019). Similar evaluations were made for tea plantations in different countries (Chakraborty et al., 2009; 2015, Mishra et al., 2014; Dutta et al., 2015). At the end of the studies, it was determined that the most characteristic bacterial species of the tea rhizosphere were Bacillus, Pseudomonas, and Paenibacillus in the diagnosis made by the MIDI system. In addition, Bacillus, Pseudomonas, Paenibacillus, Stenotrophomonas, Brevibacillus, and Arthrobacter genera include the most prominent culturable isolates in rhizosphere and soil populations in tea plantations in Trabzon and Rize provinces in the Eastern Black Sea Region. In the acidic tea rhizosphere, Bacillus cereus, Pseudomonas fluorescens, Bacillus megaterium, $S$. maltophilia, Pseudomonas putida, Bacillus licheniformis, Bacillus pumilus, Bacillus subtilis and Paenibacillus polymyxa are the most dominant nitrogen fixing- phosphate solubilizing, ACC deaminase producing species (Çakmakçı et al., 2010; Ertürk et.al., 2010 and 2014; Çakmakçı, 2019).

This research was conducted by applying 12 different biological fertilizer candidates, which were obtained from tea plantations formed by soils with $\mathrm{pH}$ levels between 3.5-6.1, and for which all tests were performed, as triple bacterial combinations, with 7 different carriers, on 2-years-old seedlings belonging to Pazar-20 tea clone. This study was carried out to determine the effects of these applications on the leaf enzymes of the plants. 


\section{MATERIAL AND METHOD}

In this study, Bacillus atrophaeusRC11, Bacillus megateriumRC07, Bacillus megaterium42/4, Bacillus megaterium21/3, Pseudomonas fluorescensRC77, Pseudomonas fluorescens8/4, Pseudomonas fluorescens8/ 6, Pseudomonas fluorescens9/7, Bacillus subtilisRC63, Bacillus subtilis39/3, Bacillus subtilis36/10, Bacillus subtilisRC521, in total 12 different isolates (belonging to 4 different species), 5 different biological fertilizer formulations were formed, 3 for each formulation. Along with these applications, 1 standard biofertilizer, standard NPK fertilizer dose (1400 mg 25:5:10/seedling), and control (without fertilizer and bacteria) were included in the study. In the study, these formulations were used in combination with 7 different carriers. Thus, the study was planned according to the factorial experiment design with 4 replications and 5 seedlings (2 years-old seedlings in pots) in each replication ( 8 applications $x 7$ carriers). Some laboratory test results of the isolates used in the study are given in Table 1.

Table 1. Some characteristics of bacteria in the combinations used in the experiment with two-year-old seedlings in the Pazar-20 tea clone.

Çizelge 1. Bakteri kombinasyonlarının laboratuvar test sonuçları.

\begin{tabular}{|c|c|c|c|c|c|c|c|c|}
\hline $\begin{array}{c}\text { Strain } \\
\text { No }\end{array}$ & MIS Diagnostic Result & Comb. & $\begin{array}{c}\text { OK } \\
\text { test }\end{array}$ & $\begin{array}{l}\text { CAT } \\
\text { test }\end{array}$ & $\begin{array}{c}\mathbf{N} \\
\text { fixation }\end{array}$ & $\begin{array}{c}\text { Sucroz } \\
\text { test }\end{array}$ & $\begin{array}{c}\text { Phosphate } \\
\text { Solubilization }\end{array}$ & ACCD \\
\hline $\mathrm{RC} 11$ & Bacillus atrophaeus & F1 & $Z+$ & $\mathrm{K}+$ & + & + & + & 2 \\
\hline $\mathrm{RCO} 7$ & Bacillus megaterium & & $Z+$ & $\mathrm{K}+$ & + & - & $\mathrm{K}+$ & TY \\
\hline $\mathrm{RC} 77$ & Pseudomonas fluorescens & & $\mathrm{K}+$ & + & $Z+$ & - & + & 2 \\
\hline RC63 & Bacillus subtilis & $\mathrm{F} 2$ & + & $\mathrm{K}+$ & $\mathrm{K}+$ & - & $Z+$ & 3 \\
\hline $21 / 3$ & Bacillus megaterium & & - & + & $\mathrm{K}+$ & - & $\mathrm{K}+$ & 2 \\
\hline $8 / 4$ & Pseudomonas fluorescens & & $\mathrm{K}+$ & $Z+$ & + & $\mathrm{K}+$ & + & 3 \\
\hline $36 / 10$ & Bacillus subtilis & F3 & - & $\mathrm{K}+$ & $\mathrm{K}+$ & + & + & 6 \\
\hline $42 / 2$ & Bacillus megaterium & & - & + & + & - & + & TY \\
\hline $8 / 6$ & Pseudomonas fluorescens & & $\mathrm{K}+$ & $\mathrm{K}+$ & + & $Z+$ & $\mathrm{K}+$ & 2 \\
\hline $39 / 3$ & Bacillus subtilis, & F4 & $Z+$ & $\mathrm{K}+$ & $\mathrm{K}+$ & + & $Z+$ & 4 \\
\hline $42 / 4$ & Bacillus megaterium & & - & + & $\mathrm{K}+$ & - & + & 8 \\
\hline $9 / 7$ & Pseudomonas fluorescens & & + & + & $\mathrm{K}+$ & $\mathrm{K}+$ & + & 2 \\
\hline RC521 & Bacillus subtilis & F5 & - & $\mathrm{K}+$ & $\mathrm{K}+$ & + & - & 3 \\
\hline $42 / 4$ & Bacillus megaterium & & - & + & $\mathrm{K}+$ & - & + & 8 \\
\hline $9 / 7$ & Pseudomonas fluorescens & & + & + & $\mathrm{K}+$ & $\mathrm{K}+$ & + & 2 \\
\hline
\end{tabular}

OK: oxidase; CAT: catalase; ACC: aminocyclopropane carboxylate deaminase activity (2 strong positive, 8 weak positive); TY: not tested; + : positive, $\mathrm{K}+$ : strongly positive; $\mathrm{Z}+$ : weak positive

The carrier formulas used in the experiment and some of their components (comprehensive ingredients and compositions are unique to this research and carrier determination studies have been continued until the most suitable liquid and solid carriers are concretely revealed):

1. (K): Tea compost-based carrier (compost, animal manure, clampe, etc.)

2. (T): Solid peat-based carrier (peat, glycerol, etc.)

3. (P): Solid perlite-based carrier (perlite, peat, clampe, glycerol, etc.)

4. (L): Solid leonardite-based carrier (leonardite, clampe etc.)

5. (Z): Solid zeolite-based carrier (zeolite, vermiculite, clampe, etc.)

6. (V): Solid vermiculite-based carrier (vermiculite, clampe, etc.)

7. (S): Liquid-based organic carrier (whey, seaweed, grass juice, etc.)

\section{Extraction Preparation, Enzyme Activity, and Determination of Protein Content}

Approximately $2 \mathrm{~g}$ leaf samples taken from tea plants were wrapped in aluminum foils and frozen at $-80^{\circ} \mathrm{C}$ until used. For analysis, $2 \mathrm{~g}$ of leaf sample was pulverized with liquid nitrogen, $10 \mathrm{~mL}$ buffer was added ( $50 \mathrm{mM}$ Tris- $\mathrm{HCl}$ and $1 \mathrm{mM}$ EDTA, $\mathrm{pH} 7.5)$, the mixture was centrifuged at $4^{\circ} \mathrm{C}$ for 20 minutes $(15,000 \mathrm{~g})$ and macroparticles were removed. precipitated and the precipitate was discarded. The supernatant was used as a crude extract for measuring of enzyme activities and protein determinations. Each enzyme activity was determined spectrophotometrically (Shimadzu Spectrophotometer UV-1208) at $25^{\circ} \mathrm{C}$. the protein concentration was calculated according to the Bradford method (1976) using bovine serum albumin as a standard using $595 \mathrm{~nm}$ absorbance measurement. Leaf enzyme measurements were repeated three times in each sample. 


\section{Assay Peroxidase (POD)}

Peroxidase (POD) activity determination is based on monitoring the absorbance increase at $470 \mathrm{~nm}$, caused by the colored compound, which is the product of the reaction in which guaiacol $\mathrm{H}_{2} \mathrm{O}_{2}$ is the substrate (Angelini et al., 1990). Various fresh plant materials were extracted in $0.1 \mathrm{M} \mathrm{pH}=7.0$ cold phosphate buffer by applying 100 $\mathrm{mg}$ fresh weight $/ \mathrm{mL}$ ratio, the extracts were centrifuged at $10000 \mathrm{rpm}$ for 15 minutes and the supernatants were taken and used for enzyme determination (Smith et al., 1971). In addition, $100 \mathrm{~mL}$ of $0.1 \mathrm{M}$ phosphate buffer with pH 5.8 was taken and $15 \mathrm{mM}$ guaiacol, $5 \mathrm{mM} \mathrm{H}_{2} \mathrm{O}_{2}$ were added and this reagent was freshly prepared and used. $3 \mathrm{~mL}$ of this reagent and $50 \mu \mathrm{L}$ of the sample according to enzyme activity were taken from the extracts and the oxidation product was measured at $470 \mathrm{~nm}$ at 10 -second intervals for 2 minutes. The increase in absorbance was recorded at 1-minute intervals, and the increase in absorbance in the part where the absorbance increased linearly was proportional to 1 minute. The amount of enzyme that increases the absorbance by 0.01 in 1 minute at $25^{\circ} \mathrm{C}$ was accepted as 1 enzyme unit, and the results were expressed as enzyme units per $\mathrm{g}$ of leaf (EU $\left.\mathrm{g} \mathrm{leaf}{ }^{-1}\right)$ (Yee et al., 2003) POD (EU g leaf $\left.{ }^{-1}\right)=(5 \mathrm{~mL}$ homegenate $/ 0.5 \mathrm{~g}$ leaf $) / 10 \mu$ ingested homogenate $) \times 2 \times(1 / 0.01) \times$ Absorbance value; POD $\left(E U\right.$ g leaf $\left.^{-1}\right)=1000 \times 100 \times$ Absorbance value. Secondly, in the POD reaction system, 0.05 $\mathrm{mL}$ enzyme extract, $2 \mathrm{~mL}$ water, $1 \mathrm{~mL}$ guaiacol as a donor, and $1 \mathrm{~mL} \mathrm{H} \mathrm{O}_{2}$ as substrate was kept in $35^{\circ} \mathrm{C}$ water for 5 minutes and measured spectrophotometrically. POD activity was defined as 0.1 units of absorbance change per minute (Mei et al., 2009).

\section{Assay Polyphenol oxidase (PPO)}

Catechol was used as a substrate. The reaction mixture; It was formed from $2 \mathrm{~mL}$ of phosphate buffer solution $(\mathrm{pH} 6.2,0.05 \mathrm{M})+0.5 \mathrm{~mL}$ of "enzyme-containing solution" + $0.5 \mathrm{~mL}$ of substrate $(0.5 \mathrm{M})$ solution (Lee et al., 1991). After the reaction mixture was incubated for 5 minutes at $30^{\circ} \mathrm{C}$, absorbance measurements were made at a wavelength of $410 \mathrm{~nm}$ at 15 -second intervals. For this purpose, the a spectrophotometer was used. The slope of the curve reflecting the absorbance $x$ time relationship was calculated in terms of "Absorbance $\mathrm{min}-1 \mathrm{~mL}-1$ " and expressed as "activity level" (Lee et al., 1991). In addition, in the reaction system of PPO enzyme extract, $1 \mathrm{~mL}$ of enzyme-containing $2 \mathrm{~mL}$ of citrate and phosphate buffer solution $(\mathrm{pH}=5.6,0.1 \mathrm{M}), 0.4 \mathrm{~mL}$ of proline $(10 \mathrm{mg} / \mathrm{mL})$ and $1 \mathrm{~mL}$ of catechol were 10 in $35{ }^{\circ} \mathrm{C}$ water. minutes and measured spectrophotometrically. The unit of PPO activity is defined as 0.1 absorbances per minute (Mei et al., 2009).

\section{Assay Urease}

For the at $37^{\circ} \mathrm{C}$ for 5 minutes. $0.5 \mathrm{~mL}(0.05 \mathrm{M})$ of urea was added to this sample and the entire mixture was left to stand for 20 minutes. $0.2 \mathrm{~mL}(1 \%)$ indophenol solution was added and $0.2 \mathrm{~mL}(0.5 \mathrm{M} \mathrm{NaOH}$ and $0.075 \%$ $\mathrm{NaOCl}$ ) reagent was added, it waited for 30 minutes and the increase in absorbance was measured by spectrophotometer at $640 \mathrm{~nm}$ (Weatherburn, 1967).

\section{Assay 5-Dehydroxyshikimate reductase}

The absorbance of NADPH2, which is formed according to the reaction Shikimat + NADP + > 5dehydroshikimate + NADPH", is based on spectrophotometric monitoring at $340 \mathrm{~nm}$ (Sanderson, 1966). The reaction mixture contains $1 \mathrm{mM}$ shikimic acid, $170 \mu \mathrm{M}$ NADP + and $0.1 \mathrm{~mL}$ enzyme solution in $2.5 \mathrm{~mL} 0.1 \mathrm{M}$ glycine buffer $(\mathrm{pH}=10)$. An enzyme unit is defined as the amount of enzyme that catalyzes the oxidation of $1 \mu \mathrm{mol}$ of shikimic acid in 1 minute.

\section{Assay Alcohol dehydrogenase activity (ADH)}

For the enzyme activity determination, the tea sample was homogenized with $10 \mathrm{~mL}$ of phosphate buffer $(0.1$ $\mathrm{M}, \mathrm{pH}=7.0$ ) and centrifuged for 15 minutes at $3000 \mathrm{rpm}$ at $+4^{\circ} \mathrm{C}$ (Smith et al., 1971). $0.2 \mathrm{~mL}$ of the supernatant was taken and NAD+ (nicotinamide adenine dinucleotide) $(2.5 \mathrm{mM})$ and ethyl alcohol $(10 \mathrm{mM})$ solution were added to the reaction medium to form the concentrations in the measuring cuvettes, and the change in absorbance per minute was measured in a spectrophotometer at $340 \mathrm{~nm}$ at $25^{\circ} \mathrm{C}$. Enzyme activity was expressed as optical density change per minute (DOD 340/g tea/min) (Smith et al., 1971; Hatanaka et al., 1974).

\section{Assay Glucose 6-phosphate dehydrogenase (G6PD)}

G6PD activity in tea leaf samples was determined according to the Beutler method (Beutler, 1984). The procedure contains $0.1 \mathrm{mM}$ Tris-HCl buffer ( $\mathrm{pH}=7.5), 0.5 \mathrm{mM}$ EDTA, $0.2 \mathrm{mM} \mathrm{NADP+}$, and $0.6 \mathrm{mM}$ G6P for G6PD, $0.6 \mathrm{mM}$ 6PGA for 6PGD, and the volume is $1 \mathrm{~mL}$. In the system, the enzyme unit is defined as $1 \mu \mathrm{mol}$ NADP+ reduction per minute. 


\section{Assay 6-phosphogluconate dehydrogenase (6PGD)}

6PGD activity in tea leaves was determined according to the Beutler method (Beutler, 1984). The procedure contains $0.1 \mathrm{mM}$ Tris-HCl buffer ( $\mathrm{pH}=7.5), 0.5 \mathrm{mM}$ EDTA, $0.2 \mathrm{mM}$ NADP+, and $0.6 \mathrm{mM}$ G6P for G6PD, $0.6 \mathrm{mM}$ 6PGA for 6PGD, and the volume is $1 \mathrm{~mL}$. In the system, the enzyme unit min is defined as $1 \mu \mathrm{mol}$ NADP+ reduction. Leaf enzyme activity was determined spectrophotometrically.

\section{Assay Glutathione reductase (GR)}

GR activity in tea leaves was determined according to the method developed by Carlberg and Mannervik (1985). Leaf enzyme activity was determined spectrophotometrically. The system contains a total volume of $1 \mathrm{~mL}$ of $0.75 \mathrm{mM}$ Tris- $\mathrm{HCl}$ buffer ( $\mathrm{pH}=7.0), 1 \mathrm{mM}$ EDTA, $1 \mathrm{mM}$ GSSG and $0.1 \mathrm{mM} \mathrm{NADPH}$. One enzyme unit is defined as the oxidation of $1 \mu \mathrm{mol}$ of NADPH per minute.

\section{Assay Glutathione S-transferase (GST)}

Leaf GST enzyme activity was determined spectrophotometrically. Glutathione S-transferase activity in tea leaves prepared by using the method given above, Habig et al. (1974), $1 \mathrm{~mL}$ volume of reaction medium contained $0.1 \mathrm{M}$ potassium phosphate buffer $(\mathrm{pH}=6.5), 1.0 \mathrm{mM} \mathrm{GSH}, 1.0 \mathrm{mM} \mathrm{CDNB}$, and $1 \%$ pure ethanol. An enzyme unit was defined as the formation of $1 \mu \mathrm{mol}$ of GS-DNB (glutathione-dinitrobenzene complex) per minute at $340 \mathrm{mn}$.

\section{Statistical Evaluations}

After the data determined in the pot experiments were statistically analyzed using STATISTICA (StatSoft-2003) and SPSS (IBM SPSS Statistics 20) programs (especially by making variance, correlation, and multiple comparison tests), significant differences between treatments were determined using Duncan's multiple range test with a significance level of $p \leq 0.05$.

\section{RESULTS AND DISCUSSION}

In this experiment, polyphenol oxidase, peroxidase and urease, alcohol dehydrogenase, and 5-de-hydroxy shikimate reductase enzyme activity tests were completed in the samples taken in May. Although the inoculated bacteria varied depending on the fertilizer applications and the carriers used, the inoculated bacterial formulations, fertilizer applications, and carriers significantly affected the leaf enzyme activity in tea seedlings (Table 2).

There are different enzymes in the root as well as in the leaves and shoots of the tea plant. Polyphenol oxidase (PPO) in tea leaves plays a role in the oxidation of flavonols, formation of taste and color, peroxidase (POD) oxidation of flavonols and alcohol dehydrogenase (ADH) in the formation of some alcohols and the development of aroma (Çalıkoğlu and Bayrak, 2009). The polyphenol oxidase (PPO) and peroxidase (POD) enzymes in the leaf play an important role in oxidation reactions and provide the formation of substances that give black tea its color and smell. Aroma compounds are formed as a result of the oxidation of tea flavonols by the enzyme polyphenol oxidase. In black tea production, catechins are oxidized under the catalysis of polyphenol oxidase enzyme and turn into theaflavin (TF) and thearubigin (TR) pigments, which give black tea its typical color and taste (Ertürk et al., 2010; Çakmakçı et al., 2017). According to the carriers averages, all treatments except the F1 formulation significantly increased the PPO and POD activities measured as enzyme units per leaf weight (EU $\mathrm{g} \mathrm{leaf}^{-1}$ ) compared to the control. PPO activity per unit protein increased with all treatments, but the rate of increase was found to be significant only with mineral fertilizer applications. Inoculations of F2, F3, and F4 formulations, especially the $\mathrm{F} 5$ formulation, significantly increased the enzyme activity in unit protein while urease activity in tea leaves increased significantly with applications other than F1 in terms of unit leaf weight, applications other than F1 and F2 increased urease activity per unit protein, and the rate of increase was found to be significant. The applications tested in this trial set did not have any effect on the increase in alcohol dehydrogenase activity. The applications in the trial set increased the activity of the 5-5-de-hydroxy shikimate reductase enzyme measured in the leaves, and the increasing rates were found to be significant in F4 and F5 applications compared to the control. All treatments significantly increased the enzyme content per protein (EU mg protein ${ }^{-1}$ ). According to the fertilizer application averages, compost, leonardite, peat, and liquid carriers gave the most appropriate results in terms of enzyme activity measurements in 2014 (Table 2,3). 
Table 2. The effect of different carriers, bacteria combinations and NPK application on polyphenol oxidase, peroxidase and urease enzyme activity in Pazar-20 tea clone (2014).

Çizelge 2. Farklı taşıyıcı, bakteri kombinasyonları ve NPK uygulamasının Pazar-20 çay klonunda polifenol oksidaz, peroksidaz ve üreaz enzim aktivitesi üzerine etkisi (2014).

\begin{tabular}{|c|c|c|c|c|c|c|c|}
\hline \multirow[b]{2}{*}{ Treatment } & \multirow[b]{2}{*}{ Carrier } & \multicolumn{2}{|c|}{ PPO } & \multicolumn{2}{|c|}{ POD } & \multicolumn{2}{|c|}{ Ürease } \\
\hline & & $\left(\text { EU g leaf }{ }^{-1}\right)^{*}$ & $\begin{array}{l}\text { (EU mg } \\
\left.\text { Protein }^{-1}\right)\end{array}$ & $\left(\right.$ EU g leaf $\left.{ }^{-1}\right)$ & $\begin{array}{l}\text { (EU/mg } \\
\text { protein) }\end{array}$ & $\left(\right.$ EU g leaf $\left.{ }^{-1}\right)$ & $\begin{array}{l}\text { (EU mg } \\
\text { Protein }^{-1} \text { ) }\end{array}$ \\
\hline \multirow[t]{8}{*}{ Control } & K & $7.78 \mathrm{k}-\mathrm{n}$ & $0.073 \mathrm{~cd}$ & $15.55 \mathrm{~h}-\mathrm{I}$ & $0.115 \mathrm{~d}-\mathrm{g}$ & 0.93 I-n & $0.0117 \mathrm{~h}-\mathrm{j}$ \\
\hline & $T$ & 8.32 i-n & $0.078 \mathrm{~cd}$ & $16.62 \mathrm{e}-\mathrm{I}$ & $0.126 \mathrm{~d}-\mathrm{g}$ & $0.99 \mathrm{i}-\mathrm{n}$ & $0.0125 \mathrm{f}-\mathrm{j}$ \\
\hline & $P$ & $7.38 \mathrm{I}-\mathrm{n}$ & $0.069 \mathrm{~cd}$ & $14.73 \mathrm{i}-\mathrm{I}$ & $0.107 \mathrm{e}-\mathrm{g}$ & $0.88 n$ & $0.0111 \mathrm{ij}$ \\
\hline & L & $8.11 j-n$ & $0.076 \mathrm{~cd}$ & $16.21 \mathrm{~g}-\mathrm{I}$ & $0.122 \mathrm{~d}-\mathrm{g}$ & $0.97 j-n$ & $0.0122 \mathrm{f}-\mathrm{j}$ \\
\hline & Z & $8.25 \mathrm{j}-\mathrm{n}$ & $0.077 \mathrm{~cd}$ & $16.47 \mathrm{e}-1$ & $0.125 \mathrm{~d}-\mathrm{g}$ & $0.98 j-n$ & $0.0124 \mathrm{f}-\mathrm{j}$ \\
\hline & V & $8.14 j-n$ & $0.076 \mathrm{~cd}$ & $16.27 \mathrm{~g}-\mathrm{I}$ & $0.123 \mathrm{~d}-\mathrm{g}$ & $0.97 j-n$ & $0.0122 \mathrm{f}-\mathrm{j}$ \\
\hline & $\mathrm{S}$ & $7.82 \mathrm{k}-\mathrm{n}$ & $0.073 \mathrm{~cd}$ & $15.63 \mathrm{~g}-1$ & $0.116 \mathrm{~d}-\mathrm{g}$ & $0.93 \mathrm{I}-\mathrm{n}$ & $0.0118 \mathrm{~g}-\mathrm{j}$ \\
\hline & Average & $7.97 \mathrm{e}$ & $0.074 \mathrm{~b}$ & $15.93 \mathrm{~d}$ & $0.119 \mathrm{~d}$ & 0.95 e & $0.0120 \mathrm{e}$ \\
\hline \multirow[t]{8}{*}{ NPK } & $\mathrm{K}$ & $9.56 \mathrm{~g}-\mathrm{j}$ & $0.249 a$ & $19.18 d-I$ & $0.137 \mathrm{~d}-\mathrm{g}$ & $1.17 b-n$ & 0.0140 c-j \\
\hline & $\mathrm{T}$ & 9.05 e-k & $0.087 \mathrm{~cd}$ & $18.35 \mathrm{~d}-\mathrm{I}$ & $0.131 \mathrm{~d}-\mathrm{g}$ & $1.12 \mathrm{~d}-\mathrm{n}$ & $0.0134 c-j$ \\
\hline & $P$ & $8.17 j-n$ & $0.079 \mathrm{~cd}$ & $16.56 \mathrm{e}-\mathrm{I}$ & $0.118 \mathrm{~d}-\mathrm{g}$ & $1.01 \mathrm{~g}-\mathrm{n}$ & $0.0121 \mathrm{f}-\mathrm{j}$ \\
\hline & L & $8.34 \mathrm{i}-\mathrm{n}$ & $0.079 \mathrm{~cd}$ & $17.32 \mathrm{~d}-\mathrm{I}$ & $0.124 \mathrm{~d}-\mathrm{g}$ & $1.06 \mathrm{f}-\mathrm{n}$ & $0.0126 e-j$ \\
\hline & Z & $8.69 \mathrm{~g}-\mathrm{n}$ & $0.084 \mathrm{~cd}$ & $17.63 \mathrm{~d}-\mathrm{I}$ & $0.126 \mathrm{~d}-\mathrm{g}$ & $1.08 d-n$ & $0.0129 \mathrm{~d}-\mathrm{j}$ \\
\hline & V & $9.67 c-j$ & $0.093 \mathrm{~cd}$ & $19.60 \mathrm{~d}-\mathrm{I}$ & $0.140 \mathrm{c}-\mathrm{g}$ & $1.20 \mathrm{~b}-\mathrm{m}$ & $0.0143 c-i$ \\
\hline & $\mathrm{S}$ & $10.13 c-h$ & $0.097 \mathrm{~cd}$ & $20.54 c-i$ & $0.147 \mathrm{~b}-\mathrm{g}$ & $1.25 \mathrm{~b}-\mathrm{k}$ & 0.0150 a-h \\
\hline & Average & 9.09 b-d & 0.110 a & 18.45 bc & 0.132 b-d & $1.13 \mathrm{~b}-\mathrm{d}$ & $0.0135 b-d$ \\
\hline \multirow[t]{8}{*}{ F1 } & $\mathrm{K}$ & 8.58 h-n & $0.059 \mathrm{~cd}$ & 22.74 b-c & $0.139 \mathrm{c}-\mathrm{g}$ & $1.13 c-n$ & $0.0130 \mathrm{~d}-\mathrm{j}$ \\
\hline & $\mathrm{T}$ & $8.10 j-n$ & $0.078 \mathrm{~cd}$ & $16.42 \mathrm{f}-\mathrm{I}$ & $0.117 \mathrm{~d}-\mathrm{g}$ & $1.00 \mathrm{~h}-\mathrm{n}$ & $0.0120 \mathrm{f}-\mathrm{j}$ \\
\hline & $P$ & $7.26 \mathrm{n}$ & $0.070 \mathrm{~cd}$ & $14.32 \mathrm{j}-\mathrm{I}$ & $0.102 \mathrm{~g}$ & $0.87 \mathrm{n}$ & $0.0104 \mathrm{j}$ \\
\hline & L & $8.71 \mathrm{~g}-\mathrm{n}$ & $0.084 \mathrm{~cd}$ & $17.66 \mathrm{~d}-\mathrm{I}$ & $0.126 \mathrm{~d}-\mathrm{gj}$ & $1.08 \mathrm{~d}-\mathrm{n}$ & $0.0129 d-j$ \\
\hline & Z & $9.16 \mathrm{~d}-\mathrm{k}$ & $0.088 \mathrm{~cd}$ & $18.58 d-I$ & $0.133 \mathrm{~d}-\mathrm{g}$ & $1.13 c-n$ & $0.0136 c-j$ \\
\hline & V & 7.74 k-n & $0.074 \mathrm{~cd}$ & $15.70 \mathrm{~g}-\mathrm{I}$ & $0.112 \mathrm{~d}$-gj & 0.96 k-n & $0.0115 \mathrm{~h}-\mathrm{j}$ \\
\hline & $\mathrm{S}$ & $9.23 \mathrm{~d}-\mathrm{k}$ & $0.089 \mathrm{~cd}$ & $18.71 \mathrm{~d}-\mathrm{I}$ & $0.134 \mathrm{~d}-\mathrm{g}$ & $1.14 c-n$ & $0.0137 c-j$ \\
\hline & Average & $8.40 \mathrm{e}$ & $0.077 \mathrm{ab}$ & $17.73 \mathrm{~cd}$ & $0.124 \mathrm{~cd}$ & $1.05 \mathrm{de}$ & $0.0124 \mathrm{de}$ \\
\hline \multirow[t]{8}{*}{$\mathrm{F} 2$} & $\mathrm{~K}$ & $7.28 \mathrm{mn}$ & $0.195 \mathrm{ab}$ & $33.91 \mathrm{a}$ & $0.226 \mathrm{a}$ & $1.01 \mathrm{~g}-\mathrm{n}$ & $0.0121 \mathrm{f}-\mathrm{j}$ \\
\hline & $T$ & $10.66 \mathrm{~cd}$ & $0.102 \mathrm{~cd}$ & $21.62 \mathrm{~b}-\mathrm{g}$ & $0.155 \mathrm{~b}-\mathrm{e}$ & $1.32 \mathrm{a}-\mathrm{g}$ & $0.0158 a-f$ \\
\hline & $P$ & 7.94 k-n & $0.076 \mathrm{~cd}$ & $16.10 \mathrm{~g}-\mathrm{I}$ & $0.115 \mathrm{~d}-\mathrm{g}$ & $0.98 j-n$ & $0.0118 \mathrm{~g}-\mathrm{j}$ \\
\hline & L & $10.30 \mathrm{c}-\mathrm{g}$ & $0.099 \mathrm{~cd}$ & $20.89 c-h$ & $0.149 \mathrm{~b}-\mathrm{g}$ & $1.27 \mathrm{~b}-\mathrm{j}$ & $0.0152 a-h$ \\
\hline & Z & $9.13 \mathrm{~d}-\mathrm{k}$ & $0.088 \mathrm{~cd}$ & $18.52 \mathrm{~d}-\mathrm{I}$ & $0.132 \mathrm{~d}-\mathrm{g}$ & $1.13 c-n$ & $0.0135 c-j$ \\
\hline & V & $7.29 \mathrm{I}-\mathrm{n}$ & $0.070 \mathrm{~cd}$ & $13.98 \mid$ & $0.105 \mathrm{fg}$ & $0.88 n$ & $0.0104 j$ \\
\hline & $\mathrm{S}$ & $9.34 \mathrm{~d}-\mathrm{k}$ & $0.090 \mathrm{~cd}$ & $18.95 \mathrm{~d}-\mathrm{I}$ & $0.136 \mathrm{~d}-\mathrm{g}$ & $1.16 c-n$ & $0.0138 c-j$ \\
\hline & Average & $8.85 \mathrm{~cd}$ & $0.103 \mathrm{ab}$ & $20.57 \mathrm{ab}$ & $0.145 a b$ & $1.11 \mathrm{~cd}$ & 0.0132 c-e \\
\hline \multirow[t]{8}{*}{ F3 } & $\mathrm{K}$ & 9.03 e-k & $0.087 \mathrm{~cd}$ & $18.31 \mathrm{~d}-\mathrm{I}$ & $0.131 \mathrm{~d}-\mathrm{g}$ & $1.12 d-n$ & $0.0134 c-j$ \\
\hline & $T$ & $9.90 c-i$ & $0.095 \mathrm{~cd}$ & $20.07 d-k$ & $0.144 \mathrm{~b}-\mathrm{g}$ & $1.23 b-m$ & $0.0146 c-i$ \\
\hline & $P$ & $9.08 d-k$ & $0.087 \mathrm{~cd}$ & $18.40 \mathrm{~d}-\mathrm{I}$ & $0.132 \mathrm{~d}-\mathrm{g}$ & $1.12 c-n$ & $0.0134 c-j$ \\
\hline & L & $12.14 a b$ & $0.161 \mathrm{~b}-\mathrm{d}$ & $22.60 \mathrm{bc}$ & $0.162 \mathrm{~b}-\mathrm{d}$ & $1.38 \mathrm{a}-\mathrm{d}$ & $0.0165 \mathrm{a}-\mathrm{d}$ \\
\hline & Z & 8.59 h-n & $0.083 \mathrm{~cd}$ & $17.43 \mathrm{~d}-\mathrm{I}$ & $0.125 \mathrm{~d}-\mathrm{g}$ & $1.06 \mathrm{e}-\mathrm{n}$ & $0.0127 \mathrm{~d}-\mathrm{j}$ \\
\hline & V & $9.36 \mathrm{~d}-\mathrm{k}$ & $0.090 \mathrm{~cd}$ & $18.98 \mathrm{~d}-\mathrm{I}$ & $0.136 \mathrm{~d}-\mathrm{g}$ & $1.16 b-n$ & $0.0138 c-j$ \\
\hline & $\mathrm{S}$ & $10.28 c-g$ & $0.099 \mathrm{~cd}$ & $20.84 c-h$ & $0.149 \mathrm{~b}-\mathrm{g}$ & $1.27 \mathrm{~b}-\mathrm{j}$ & $0.0152 a-h$ \\
\hline & Average & $9.77 \mathrm{ab}$ & $0.100 \mathrm{ab}$ & 19.52 bc & 0.140 a-c & $1.19 \mathrm{a}-\mathrm{c}$ & $0.0142 a-c$ \\
\hline \multirow[t]{8}{*}{ F4 } & $\mathrm{K}$ & $12.63 \mathrm{a}$ & $0.122 b-d$ & $26.63 \mathrm{~b}$ & $0.190 \mathrm{ab}$ & $1.58 \mathrm{a}$ & $0.0186 \mathrm{a}$ \\
\hline & $T$ & $10.19 c-h$ & $0.098 \mathrm{~cd}$ & $20.65 c-i$ & $0.148 \mathrm{~b}-\mathrm{g}$ & $1.26 \mathrm{~b}-\mathrm{k}$ & $0.0151 a-h$ \\
\hline & $P$ & 7.93 k-n & $0.076 \mathrm{~cd}$ & $16.09 \mathrm{~g}-1$ & $0.115 \mathrm{~d}-\mathrm{g}$ & $0.98 j-n$ & $0.0117 \mathrm{~g}-\mathrm{j}$ \\
\hline & L & $9.63 c-j$ & $0.093 \mathrm{~cd}$ & $19.53 \mathrm{~d}-\mathrm{I}$ & $0.140 \mathrm{c}-\mathrm{g}$ & $1.19 \mathrm{~b}-\mathrm{m}$ & $0.0142 c-i$ \\
\hline & Z & $10.57 \mathrm{c}-\mathrm{e}$ & $0.102 \mathrm{~cd}$ & $21.43 b-h$ & $0.153 b-f$ & $1.31 a-h$ & $0.0156 \mathrm{a}-\mathrm{f}$ \\
\hline & V & $10.01 c-h$ & $0.096 \mathrm{~cd}$ & $20.30 \mathrm{~d}-\mathrm{j}$ & $0.145 \mathrm{~b}-\mathrm{g}$ & 1.24 b-I & $0.0148 b-i$ \\
\hline & $\mathrm{S}$ & $11.06 \mathrm{bc}$ & $0.106 \mathrm{~b}-\mathrm{d}$ & $20.43 b-e$ & $0.160 \mathrm{~b}-\mathrm{d}$ & 1.37a-e & 0.0164 a-e \\
\hline & Average & 10.29 a & $0.099 \mathrm{ab}$ & $21.01 \mathrm{ab}$ & $0.150 \mathrm{ab}$ & $1.28 \mathrm{a}$ & $0.0152 \mathrm{a}$ \\
\hline \multirow[t]{8}{*}{ F5 } & $\mathrm{K}$ & $7.27 n$ & $0.043 \mathrm{~d}$ & $36.98 \mathrm{a}$ & $0.225 \mathrm{a}$ & $1.46 \mathrm{ab}$ & $0.0183 a b$ \\
\hline & $T$ & $8.89 \mathrm{f}-\mathrm{I}$ & $0.095 \mathrm{~cd}$ & $18.03 \mathrm{~d}-\mathrm{I}$ & $0.129 \mathrm{~d}-\mathrm{g}$ & $1.10 \mathrm{~d}-\mathrm{n}$ & $0.0132 d-j$ \\
\hline & $P$ & $7.36 \mathrm{I}-\mathrm{n}$ & $0.069 \mathrm{~cd}$ & $14.32 \mathrm{j}-\mathrm{I}$ & $0.102 \mathrm{~g}$ & $0.87 \mathrm{n}$ & $0.0104 j$ \\
\hline & L & $12.82 \mathrm{a}$ & $0.123 \mathrm{~b}-\mathrm{d}$ & $25.99 \mathrm{bc}$ & $0.186 a-c$ & $1.59 \mathrm{a}$ & $0.0185 \mathrm{a}$ \\
\hline & Z & $9.16 \mathrm{~d}-\mathrm{k}$ & $0.092 \mathrm{~cd}$ & $18.17 \mathrm{~d}-\mathrm{I}$ & $0.130 \mathrm{~d}-\mathrm{g}$ & $1.11 \mathrm{~d}-\mathrm{n}$ & $0.0133 d-j$ \\
\hline & V & $11.00 \mathrm{bc}$ & $0.106 \mathrm{~b}-\mathrm{d}$ & $22.31 \mathrm{~b}-\mathrm{f}$ & $0.160 \mathrm{~b}-\mathrm{d}$ & $1.36 \mathrm{a}-\mathrm{f}$ & 0.0163 a-e \\
\hline & $\mathrm{S}$ & $10.48 c-f$ & $0.101 \mathrm{~cd}$ & $21.25 b-h$ & $0.152 \mathrm{~b}-\mathrm{g}$ & $1.30 \mathrm{~b}-\mathrm{i}$ & $0.0155 \mathrm{a}-\mathrm{g}$ \\
\hline & Average & 9.57 a-c & $0.088 \mathrm{ab}$ & 22.44 a & $0.155 a$ & $1.26 \mathrm{a}$ & 0.0151 a \\
\hline
\end{tabular}


Table 2. Continue.

Çizelge 2. Devamı.

\begin{tabular}{|c|c|c|c|c|c|c|c|}
\hline \multirow[b]{2}{*}{ Treatment } & \multirow[b]{2}{*}{ Carrier } & \multicolumn{2}{|c|}{ PPO } & \multicolumn{2}{|c|}{ POD } & \multicolumn{2}{|c|}{ Ürease } \\
\hline & & $(\text { EU g leaf-1 })^{*}$ & $\begin{array}{l}\text { (EU mg } \\
\left.\text { Protein }^{-1}\right)\end{array}$ & (EU g leaf-1) & $\begin{array}{l}\text { (EU/mg } \\
\text { protein) }\end{array}$ & (EU g leaf-1) & $\begin{array}{l}\text { (EU mg } \\
\text { Protein-1) }^{-1}\end{array}$ \\
\hline \multirow[t]{8}{*}{ Biological Fert. } & $\mathrm{K}$ & $7.35 \mathrm{I}-\mathrm{n}$ & $0.136 b-d$ & $14.15 \mathrm{kl}$ & $0.122 \mathrm{~d}-\mathrm{g}$ & $1.43 \mathrm{a}-\mathrm{c}$ & $0.0170 \mathrm{a}-\mathrm{c}$ \\
\hline & $T$ & $8.60 h-n$ & $0.083 \mathrm{~cd}$ & $17.45 d-I$ & $0.125 d-g$ & $1.06 \mathrm{e}-\mathrm{n}$ & $0.0127 d-j$ \\
\hline & $P$ & $9.89 c-i$ & $0.095 \mathrm{~cd}$ & $20.05 d-k$ & $0.143 b-g$ & 1.22 b-m & $0.0146 c-i$ \\
\hline & L & $11,03 \mathrm{bc}$ & $0.106 \mathrm{~b}-\mathrm{d}$ & $22.37 \mathrm{~b}-\mathrm{f}$ & $0.160 \mathrm{~b}-\mathrm{d}$ & $1.37 \mathrm{a}-\mathrm{f}$ & 0.0163 a-e \\
\hline & Z & $8.88 \mathrm{f}-\mathrm{m}$ & $0.085 \mathrm{~cd}$ & $18.01 \mathrm{~d}-\mathrm{I}$ & $0.129 \mathrm{~d}-\mathrm{g}$ & $1.10 d-n$ & $0.0131 d-j$ \\
\hline & V & $9.56 c-j$ & $0.092 \mathrm{~cd}$ & $19.38 d-I$ & $0.139 c-g$ & $1.18 b-n$ & $0.0141 c-j$ \\
\hline & $\mathrm{S}$ & $9.88 c-i$ & $0.095 \mathrm{~cd}$ & $20.04 d-k$ & $0.143 \mathrm{~b}-\mathrm{g}$ & $1.22 \mathrm{~b}-\mathrm{m}$ & $0.0146 c-i$ \\
\hline & Average & $9.31 \mathrm{bc}$ & $0.099 a b$ & 18.78 bc & 0.137 a-d & $1.23 \mathrm{ab}$ & $0.0147 \mathrm{ab}$ \\
\hline \multirow[t]{7}{*}{ Treatment Average } & $\mathrm{K}$ & $8.68 \mathrm{~cd}$ & $0.120 \mathrm{a}$ & $23.43 \mathrm{a}$ & $0.161 \mathrm{a}$ & $1.23 \mathrm{a}$ & $0.0148 \mathrm{a}$ \\
\hline & $T$ & 9.21 bc & $0.088 \mathrm{~b}$ & $18.65 b c$ & $0.134 \mathrm{~b}$ & $1.14 \mathrm{ab}$ & $0.0137 a b$ \\
\hline & $P$ & $8.13 d$ & $0.078 \mathrm{~b}$ & $16.32 \mathrm{c}$ & $0.117 \mathrm{c}$ & $0.99 c$ & $0.0120 c$ \\
\hline & L & $10.14 a$ & $0.102 a b$ & $20.32 b$ & $0.146 a b$ & $1.24 \mathrm{a}$ & $0.0148 a$ \\
\hline & Z & $9.06 \mathrm{bc}$ & $0.087 \mathrm{~b}$ & $18.28 b c$ & $0.132 b c$ & $1.11 \mathrm{~b}$ & $0.0134 \mathrm{~b}$ \\
\hline & V & $9.10 \mathrm{bc}$ & $0.087 \mathrm{~b}$ & $18.32 b c$ & $0.132 b c$ & 1.12 b & $0.0134 \mathrm{~b}$ \\
\hline & $\mathrm{S}$ & $9.78 \mathrm{ab}$ & $0.094 \mathrm{ab}$ & $19.80 \mathrm{~b}$ & $0.142 \mathrm{~b}$ & $1.21 \mathrm{ab}$ & $0.0145 \mathrm{ab}$ \\
\hline
\end{tabular}

*The differences between the means indicated with the same letter are not significant $(p<0.05)$ in their group.

Table 3. The effect of different carriers and treatments on alcohol dehydrogenase and 5-dehydroxyshikimate reductase enzyme activity in Pazar-20 tea clone (2013).

Çizelge 3. Farklı taşıyıcı ve uygulamaların Pazar-20 çay klonunda alkol dehidrogenaz ve 5-dehidroksişikimat redüktaz enzim aktivitesi üzerine etkisi (2013 yill).

\begin{tabular}{|c|c|c|c|c|c|}
\hline \multirow[b]{2}{*}{ Treatment } & \multirow[b]{2}{*}{ Carrier } & \multicolumn{2}{|c|}{ Alchol dehidrogenase } & \multicolumn{2}{|c|}{ 5-dehydroxyshikimate reductase } \\
\hline & & $(E U$ g leaf -1$) *$ & (EU mg protein-1) & (EU g leaf-1) & (EU mg protein ${ }^{-1}$ ) \\
\hline \multirow[t]{8}{*}{ Control } & $\mathrm{K}$ & $1.50 \mathrm{ab}$ & $0.056 \mathrm{a}$ & $2.32 \mathrm{f}-\mathrm{I}$ & $0.033 \mathrm{~h}$ \\
\hline & $\mathrm{T}$ & $1.60 \mathrm{a}$ & $0.060 \mathrm{a}$ & $2.48 d-I$ & $0.036 \mathrm{~h}$ \\
\hline & $P$ & $1.42 \mathrm{a}-\mathrm{d}$ & $0.053 \mathrm{ab}$ & $2.20 \mathrm{~h}-\mathrm{I}$ & $0.054 \mathrm{fh}$ \\
\hline & $\mathrm{L}$ & $1.56 \mathrm{a}$ & $0.058 \mathrm{a}$ & $2.42 \mathrm{~d}-1$ & $0.065 d-h$ \\
\hline & Z & $1.59 \mathrm{a}$ & $0.059 \mathrm{a}$ & $2.46 \mathrm{~d}-\mathrm{I}$ & $0.066 \mathrm{~d}-\mathrm{h}$ \\
\hline & $\mathrm{V}$ & $1.57 \mathrm{a}$ & $0.059 \mathrm{a}$ & $2.43 d-1$ & $0.067 \mathrm{~d}-\mathrm{h}$ \\
\hline & $\mathrm{S}$ & $1.51 \mathrm{ab}$ & $0.056 \mathrm{a}$ & $2.33 \mathrm{e}-\mathrm{I}$ & 0.060 e-h \\
\hline & & $1.54 \mathrm{a}$ & 0.057 a & $2.37 \mathrm{c}$ & $0.055 \mathrm{c}$ \\
\hline \multirow[t]{8}{*}{ NPK } & $\mathrm{K}$ & $0.89 \mathrm{~g}-\mathrm{k}$ & $0.029 \mathrm{~h}-\mathrm{I}$ & $2.54 \mathrm{~d}-\mathrm{I}$ & $0.081 \mathrm{c}-\mathrm{g}$ \\
\hline & $\mathrm{T}$ & $0.85 \mathrm{~g}-\mathrm{k}$ & 0.028 h-I & $2.43 \mathrm{~d}-\mathrm{I}$ & $0.078 \mathrm{c}-\mathrm{g}$ \\
\hline & $P$ & 0.77 h-k & $0.025 \mathrm{i}-\mathrm{I}$ & $2.19 \mathrm{~h}-\mathrm{I}$ & $0.070 \mathrm{~d}-\mathrm{h}$ \\
\hline & L & $0.81 \mathrm{~g}-\mathrm{k}$ & $0.026 \mathrm{~h}-\mathrm{I}$ & $2.29 \mathrm{~g}-1$ & $0.074 \mathrm{~d}-\mathrm{g}$ \\
\hline & Z & $0.82 \mathrm{~g}-\mathrm{k}$ & 0.027 h-I & $2.33 \mathrm{e}-\mathrm{I}$ & $0.075 \mathrm{c}-\mathrm{g}$ \\
\hline & V & $0.91 \mathrm{~g}-\mathrm{j}$ & $0.030 \mathrm{~h}-\mathrm{I}$ & $2.58 \mathrm{~d}-\mathrm{k}$ & $0.083 \mathrm{c}-\mathrm{g}$ \\
\hline & $S$ & $0.96 \mathrm{~g}-\mathrm{i}$ & $0.031 \mathrm{~h}-\mathrm{k}$ & $2.72 \mathrm{~d}-\mathrm{k}$ & $0.087 \mathrm{~b}-\mathrm{g}$ \\
\hline & & $0.86 \mathrm{~cd}$ & $0.028 \mathrm{~cd}$ & $2.44 \mathrm{c}$ & $0.078 \mathrm{~b}$ \\
\hline \multirow[t]{8}{*}{ F1 } & $\mathrm{K}$ & $0.91 \mathrm{~g}-\mathrm{k}$ & $0.027 \mathrm{~h}-\mathrm{I}$ & $3.92 \mathrm{a}$ & $0.124 a b$ \\
\hline & $T$ & $0.76 \mathrm{~h}-\mathrm{k}$ & $0.025 \mathrm{j}-\mathrm{I}$ & $2.17 \mathrm{i}-\mathrm{I}$ & $0.070 \mathrm{~d}-\mathrm{h}$ \\
\hline & $P$ & $0.67 \mathrm{jk}$ & 0.0221 & $1.90 \mid$ & $0.061 \mathrm{e}-\mathrm{h}$ \\
\hline & L & $0.82 \mathrm{~g}-\mathrm{k}$ & 0.027 h-I & $2.34 \mathrm{e}-\mathrm{I}$ & $0.075 \mathrm{c}-\mathrm{g}$ \\
\hline & Z & $0.86 \mathrm{~g}-\mathrm{k}$ & $0.028 \mathrm{~h}-\mathrm{I}$ & $2.46 \mathrm{~d}-\mathrm{I}$ & $0.067 \mathrm{f}$ \\
\hline & V & 0.73 i-k & $0.024 \mathrm{kl}$ & 2.08 kl & $0.067 \mathrm{~d}-\mathrm{h}$ \\
\hline & $S$ & $0.87 \mathrm{~g}-\mathrm{k}$ & $0.028 \mathrm{~h}-\mathrm{I}$ & $2.48 d-I$ & $0.079 \mathrm{c}-\mathrm{g}$ \\
\hline & & $0.80 \mathrm{~d}$ & $0.026 \mathrm{~d}$ & $2.48 \mathrm{c}$ & 0.079 b \\
\hline \multirow[t]{8}{*}{$\mathrm{F} 2$} & $\mathrm{~K}$ & $1.44 \mathrm{a}-\mathrm{c}$ & $0.048 \mathrm{bc}$ & 3.08 a-d & $0.103 \mathrm{~b}-\mathrm{e}$ \\
\hline & $\mathrm{T}$ & $1.01 \mathrm{e}-\mathrm{h}$ & $0.033 \mathrm{f}-\mathrm{g}$ & $2.86 c-h$ & $0.092 \mathrm{~b}-\mathrm{g}$ \\
\hline & $P$ & $0.75 \mathrm{~h}-\mathrm{k}$ & $0.024 \mathrm{j}-1$ & $2.13 \mathrm{j}-\mathrm{I}$ & $0.068 d-h$ \\
\hline & L & $0.97 \mathrm{f}-\mathrm{i}$ & $0.032 \mathrm{~g}-\mathrm{k}$ & $2.77 \mathrm{~d}-\mathrm{c}$ & $0.089 \mathrm{~b}-\mathrm{g}$ \\
\hline & Z & $0.86 \mathrm{~g}-\mathrm{k}$ & 0.028 h-I & $2.45 \mathrm{~d}-\mathrm{I}$ & $0.079 \mathrm{c}-\mathrm{g}$ \\
\hline & V & $0.65 \mathrm{k}$ & 0.022 I & $1.89 \mid$ & $0.059 e-h$ \\
\hline & $S$ & $0.88 \mathrm{~g}-\mathrm{k}$ & $0.029 \mathrm{~h}-\mathrm{I}$ & $2.51 \mathrm{~d}-\mathrm{I}$ & $0.080 \mathrm{c}-\mathrm{g}$ \\
\hline & & 0.94 bc & $0.031 \mathrm{bc}$ & $2.53 \mathrm{bc}$ & $0.081 \mathrm{ab}$ \\
\hline
\end{tabular}


Table 3. Continue.

Çizelge 3. Devamı.

\begin{tabular}{|c|c|c|c|c|c|}
\hline \multirow{3}{*}{ Treatment } & \multirow{3}{*}{ Carrier } & \multicolumn{2}{|c|}{ Alchol dehidrogenase } & \multicolumn{2}{|c|}{ 5-dehydroxyshikimate reductase } \\
\hline & & & & & \\
\hline & & $(E U$ g leaf -1$) *$ & $\left(\right.$ EU mg protein $\left.{ }^{-1}\right)$ & $($ EU g leaf-1) & $\left(\right.$ EU mg protein $\left.{ }^{-1}\right)$ \\
\hline \multirow[t]{7}{*}{ F3 } & $\mathrm{K}$ & $0.85 \mathrm{~g}-\mathrm{k}$ & $0.028 \mathrm{~h}-\mathrm{I}$ & $2.42 \mathrm{~d}-\mathrm{I}$ & $0.078 \mathrm{c}-\mathrm{g}$ \\
\hline & $\mathrm{T}$ & $0.93 \mathrm{~g}-\mathrm{i}$ & $0.030 \mathrm{~h}-\mathrm{I}$ & $2.66 \mathrm{~d}-\mathrm{k}$ & $0.085 \mathrm{c}-\mathrm{g}$ \\
\hline & $P$ & $0.86 \mathrm{~g}-\mathrm{k}$ & $0.028 \mathrm{~h}-\mathrm{I}$ & $2.44 \mathrm{~d}-\mathrm{I}$ & $0.078 \mathrm{c}-\mathrm{g}$ \\
\hline & $\mathrm{L}$ & $1.05 \mathrm{e}-\mathrm{g}$ & 0.034 e-h & 2.99 a-e & $0.096 b-f$ \\
\hline & Z & $0.81 \mathrm{~g}-\mathrm{k}$ & $0.026 \mathrm{~h}-\mathrm{I}$ & $2.31 \mathrm{f}-\mathrm{I}$ & $0.074 \mathrm{c}-\mathrm{g}$ \\
\hline & V & $0.88 \mathrm{~g}-\mathrm{k}$ & $0.029 \mathrm{~h}-\mathrm{I}$ & $2.51 \mathrm{~d}-\mathrm{I}$ & $0.081 \mathrm{c}-\mathrm{g}$ \\
\hline & $\mathrm{S}$ & $0.97 \mathrm{f}-\mathrm{i}$ & $0.032 \mathrm{~g}-\mathrm{k}$ & $2.76 \mathrm{~d}-\mathrm{j}$ & $0.088 \mathrm{~b}-\mathrm{g}$ \\
\hline \multicolumn{2}{|c|}{ Average } & $0.91 \mathrm{bc}$ & $0.030 \mathrm{bc}$ & 2.58 a-c & $0.083 \mathrm{ab}$ \\
\hline \multirow[t]{8}{*}{ F4 } & $\mathrm{K}$ & 1.24 c-e & $0.040 c-f$ & $3.53 \mathrm{ab}$ & $0.113 b c$ \\
\hline & $\mathrm{T}$ & $0.96 \mathrm{~g}-\mathrm{i}$ & $0.031 \mathrm{~g}-\mathrm{k}$ & $2.73 \mathrm{~d}-\mathrm{k}$ & $0.088 \mathrm{~b}-\mathrm{g}$ \\
\hline & $P$ & $0.75 \mathrm{~h}-\mathrm{k}$ & 0.024 j-I & $2.13 \mathrm{j}-\mathrm{I}$ & $0.068 d-h$ \\
\hline & $\mathrm{L}$ & $0.91 \mathrm{~g}-\mathrm{k}$ & 0.030 h-I & $2.59 \mathrm{~d}-\mathrm{k}$ & $0.083 \mathrm{c}-\mathrm{g}$ \\
\hline & Z & $1.00 \mathrm{f}-\mathrm{h}$ & $0.033 \mathrm{f}-\mathrm{k}$ & 2.84 c-i & $0.091 \mathrm{~b}-\mathrm{g}$ \\
\hline & V & $0.94 \mathrm{~g}-\mathrm{i}$ & $0.031 \mathrm{~h}-\mathrm{k}$ & $2.69 \mathrm{~d}-\mathrm{k}$ & $0.086 \mathrm{c}-\mathrm{g}$ \\
\hline & $S$ & $1.04 \mathrm{e}-\mathrm{g}$ & 0.034 e-h & $2.97 b-f$ & $0.095 b-f$ \\
\hline & age & $0.98 \mathrm{~b}$ & 0.032 b & $2.78 \mathrm{ab}$ & $0.089 \mathrm{ab}$ \\
\hline \multirow[t]{8}{*}{ F5 } & $\mathrm{K}$ & $1.32 b-d$ & $0.044 \mathrm{~cd}$ & $4.00 \mathrm{a}$ & $0.153 \mathrm{a}$ \\
\hline & $\mathrm{T}$ & $0.84 \mathrm{~g}-\mathrm{k}$ & 0.027 h-I & $2.39 \mathrm{e}-\mathrm{I}$ & $0.077 \mathrm{c}-\mathrm{g}$ \\
\hline & $P$ & $0.67 \mathrm{jk}$ & 0.022 I & 1.90 I & 0.061 e-h \\
\hline & $\mathrm{L}$ & $1.21 \mathrm{~d}-\mathrm{f}$ & $0.039 \mathrm{~d}-\mathrm{g}$ & $3.44 \mathrm{a}-\mathrm{c}$ & $0.110 \mathrm{~b}-\mathrm{d}$ \\
\hline & Z & $0.85 \mathrm{~g}-\mathrm{k}$ & $0.028 \mathrm{~h}-\mathrm{I}$ & $2.41 \mathrm{e}-\mathrm{I}$ & $0.077 \mathrm{c}-\mathrm{g}$ \\
\hline & V & $1.04 \mathrm{e}-\mathrm{g}$ & 0.034 e-h & $2.95 \mathrm{~b}-\mathrm{g}$ & $0.095 b-f$ \\
\hline & $S$ & $0.99 \mathrm{f}-\mathrm{i}$ & $0.032 \mathrm{~g}-\mathrm{k}$ & $2.81 \mathrm{~d}-\mathrm{i}$ & $0.090 \mathrm{~b}-\mathrm{g}$ \\
\hline & age & $0.99 \mathrm{~b}$ & $0.032 \mathrm{~b}$ & $2.84 \mathrm{a}$ & 0.095 a \\
\hline \multirow[t]{2}{*}{ Biological } & $\mathrm{K}$ & $1.21 \mathrm{~d}-\mathrm{f}$ & $0.041 \mathrm{c}-\mathrm{e}$ & $1.88 I$ & 0.063 e-h \\
\hline & $\mathrm{T}$ & $0.81 \mathrm{~g}-\mathrm{k}$ & $0.026 \mathrm{hl}$ & $2.31 \mathrm{f}-\mathrm{I}$ & $0.074 \mathrm{c}-\mathrm{g}$ \\
\hline \multirow[t]{5}{*}{ Fertilizer } & $P$ & $0.93 \mathrm{~g}-\mathrm{i}$ & $0.030 \mathrm{~h}-\mathrm{I}$ & $2.65 \mathrm{~d}-\mathrm{k}$ & $0.085 \mathrm{c}-\mathrm{g}$ \\
\hline & $\mathrm{L}$ & $1.04 \mathrm{e}-\mathrm{g}$ & 0.034 e-h & $2.96 \mathrm{~b}-\mathrm{g}$ & $0.095 b-f$ \\
\hline & Z & $0.84 \mathrm{~g}-\mathrm{k}$ & $0.027 \mathrm{~h}-\mathrm{I}$ & $2.38 \mathrm{e}-\mathrm{I}$ & $0.076 \mathrm{c}-\mathrm{g}$ \\
\hline & V & $0.90 \mathrm{~g}-\mathrm{k}$ & 0.029 h-I & $2.57 \mathrm{~d}-\mathrm{k}$ & $0.082 \mathrm{c}-\mathrm{g}$ \\
\hline & $\mathrm{S}$ & $0.93 \mathrm{~g}-\mathrm{i}$ & $0.030 \mathrm{~h}-\mathrm{I}$ & $2.65 \mathrm{~d}-\mathrm{k}$ & $0.085 \mathrm{c}-\mathrm{g}$ \\
\hline \multicolumn{2}{|c|}{ Average } & 0.95 bc & 0.031 bc & $2.49 \mathrm{c}$ & $0.080 \mathrm{~b}$ \\
\hline Treatment & K & $1.17 \mathrm{a}$ & 0.039 a & $2.96 \mathrm{a}$ & $0.094 \mathrm{a}$ \\
\hline \multirow[t]{6}{*}{ Average } & $\mathrm{T}$ & $0.97 \mathrm{bc}$ & $0.033 \mathrm{bc}$ & $2.50 \mathrm{bc}$ & $0.075 \mathrm{bc}$ \\
\hline & $P$ & $0.85 \mathrm{c}$ & $0.029 \mathrm{c}$ & $2.19 d$ & $0.068 \mathrm{c}$ \\
\hline & $\mathrm{L}$ & $1.05 a b$ & $0.035 a b$ & $2.72 \mathrm{~b}$ & $0.086 \mathrm{ab}$ \\
\hline & Z & $0.95 b c$ & $0.032 b c$ & $2.45 \mathrm{c}$ & $0.077 \mathrm{bc}$ \\
\hline & V & $0.95 \mathrm{bc}$ & 0.032 bc & $2.46 \mathrm{c}$ & 0.078 bc \\
\hline & $\mathrm{S}$ & $1.02 \mathrm{~b}$ & $0.034 \mathrm{a}-\mathrm{c}$ & $2.65 \mathrm{bc}$ & $0.083 \mathrm{ab}$ \\
\hline
\end{tabular}

${ }^{*}$ The differences between the means indicated with the same letter are not significant $(p<0.05)$ in their group.

The effects of bacteria and chemical fertilizer applications on leaf antioxidant and pentose phosphate pathway enzyme activities in seedlings of Pazar-20 tea clone are given in Table 4. As can be seen from the relevant table, enzyme activities increased in all applications except the control. This increase was generally higher in biological fertilizers. In addition, the F3 formulation was found to be quite effective in terms of GST, G6PD, and 6PGD enzyme activities. When an evaluation is made in terms of the effect of the carriers used on the leaf enzyme activities, it has been observed that the peat-based carrier is promising and the liquid carrier also affects the leaf enzyme activity (Table 4). According to the 2015 results of the leaf polyphenol oxidase, peroxidase, and urease enzyme contents in Pazar-20 tea clone seedlings, all applications increased the activity of the mentioned enzymes compared to the control (Table 5). 
Ertürk et al., Effects of Different Biological Fertilizers Formulated With Multiple Bacteria and Carriers in Pazar 20 Tea Clones on Leaf Enzyme Activity

Table 4. The effect of different carriers, mineral fertilization and bacterial combinations on leaf GR, GST, G6PD and 6PGD enzyme activity in Pazar-20 tea clone (2014).

Çizelge 4. Farklı taşıyıcı, mineral gübreleme ve bakteri kombinasyonlarının Pazar-20 çay klonunda yaprak GR, GST, G6PD ve 6PGD enzim aktivitesi üzerine etkisi (2014).

\begin{tabular}{llcll}
\hline Variation Sources & \multicolumn{4}{c}{ Enzym activity EU mg protein ${ }^{-1} *$} \\
& GR $^{* *}$ & GST & G6PD & 6PGD \\
\hline Control & $1.53 \mathrm{f}$ & $1.31 \mathrm{e}$ & $1.60 \mathrm{~d}$ & $1.09 \mathrm{~d}$ \\
NPK & $2.66 \mathrm{~b}$ & $2.36 \mathrm{ab}$ & $1.72 \mathrm{~cd}$ & $1.51 \mathrm{c}$ \\
FI & $2.39 \mathrm{c}$ & $2.27 \mathrm{bc}$ & $1.88 \mathrm{c}$ & $1.60 \mathrm{bc}$ \\
F2 & $2.17 \mathrm{e}$ & $2.13 \mathrm{~cd}$ & $1.91 \mathrm{bc}$ & $1.51 \mathrm{c}$ \\
F3 & $2.27 \mathrm{de}$ & $2.36 \mathrm{ab}$ & $2.38 \mathrm{a}$ & $1.86 \mathrm{a}$ \\
F4 & $2.35 \mathrm{~cd}$ & $2.05 \mathrm{~d}$ & $2.14 \mathrm{ab}$ & $1.64 \mathrm{ac}$ \\
F5 & $2.25 \mathrm{de}$ & $2.11 \mathrm{~cd}$ & $1.92 \mathrm{bc}$ & $1.81 \mathrm{ab}$ \\
Biological Fertilizer & $2.87 \mathrm{a}$ & $2.45 \mathrm{a}$ & $1.82 \mathrm{~cd}$ & $1.74 \mathrm{ab}$ \\
\hline \multicolumn{5}{c}{ Carriers (n=32) } \\
\hline Compost & $2.29 \mathrm{bc}$ & $2.18 \mathrm{ab}$ & $1.85 \mathrm{ab}$ & $1.66 \mathrm{a}$ \\
Peat & $2.26 \mathrm{c}$ & $2.32 \mathrm{a}$ & $1.79 \mathrm{~b}$ & $1.71 \mathrm{a}$ \\
Perlite & $2.13 \mathrm{~d}$ & $2.04 \mathrm{~b}$ & $1.91 \mathrm{ab}$ & $1.44 \mathrm{~b}$ \\
Leonardite & $2.31 \mathrm{bc}$ & $2.12 \mathrm{ab}$ & $1.91 \mathrm{ab}$ & $1.58 \mathrm{ab}$ \\
Zeolite & $2.27 \mathrm{c}$ & $2.11 \mathrm{ab}$ & $2.07 \mathrm{a}$ & $1.61 \mathrm{ab}$ \\
Vermiculite & $2.40 \mathrm{ab}$ & $2.02 \mathrm{~b}$ & $1.93 \mathrm{ab}$ & $1.59 \mathrm{ab}$ \\
Liquid Formula & $2.51 \mathrm{a}$ & $2.11 \mathrm{ab}$ & $1.98 \mathrm{ab}$ & $1.59 \mathrm{ab}$ \\
\hline
\end{tabular}

${ }^{*}$ GR: Glutation reductase, GST: Glutation S-transferase, G6PD: Glucoz-6 phosphat dehidrogenase (G6PD), 6PGD: 6-Phosphogluconat dehidrogenase (EC 1.1.1.44).

${ }^{* * *}$ The differences between the means indicated with the same letter are not significant $(p<0.05)$ in their group.

In this study, especially the F4 formulation gave the highest leaf enzyme activity among the applications. This formulation was followed by F3 and F5 in terms of effectiveness. In terms of carriers used in the study, leonardite and compost leaf gave the highest values in terms of enzyme activities (Table 5). The analysis results regarding the effect of the applications on the alcohol dehydrogenase and 5-de-hydroxy shikimate reductase enzymes in the leaf are given in Table 6. As can be seen from the table, all applications increased leaf enzyme activities compared to the control. The F5 formula increased the enzyme activities at the highest level. According to the application averages, the compost carrier gave the highest values in terms of POD, urease, ADH, and DHSK enzyme activities, followed by leonardite (Table 5,6).

Table 5. The effect of different carriers, bacterial combinations and NPK fertilizer application on polyphenol oxidase, peroxidase and urease enzyme activity in Pazar-20 tea clone (2015).

Çizelge 5. Farklı taşıyıcı, bakteri kombinasyonları ve NPK gübre uygulamasının Pazar-20 çay klonunda polifenol oksidaz, peroksidaz ve üreaz enzim aktivitesi üzerine etkisi (2015).

\begin{tabular}{|c|c|c|c|c|c|c|c|}
\hline \multirow[b]{2}{*}{ Treatment* } & \multirow[b]{2}{*}{ Carrier } & \multicolumn{2}{|c|}{ PPO } & \multicolumn{2}{|c|}{ POD } & \multicolumn{2}{|c|}{ Urease } \\
\hline & & $\left(\right.$ EU g leaf $\left.{ }^{-1}\right) *$ & $\begin{array}{l}\text { (EU mg } \\
\left.\text { Protein }{ }^{-1}\right)\end{array}$ & $\begin{array}{l}(E U \\
\left.\text { leaf }^{-1}\right)\end{array}$ & $\begin{array}{l}\text { (EU mg } \\
\left.\text { Protein }^{-1}\right)\end{array}$ & $\begin{array}{l}(\mathrm{EU} \\
\left.\text { leaf }^{-1}\right)\end{array}$ & $\begin{array}{l}\text { (EU mg } \\
\left.\text { Protein }{ }^{-1}\right)\end{array}$ \\
\hline \multirow[t]{8}{*}{ Control } & K & $8.29 \mathrm{i}$ & 0.088 a-e & $16.55 \mathrm{f}$ & $0.144 \mathrm{~d}-\mathrm{h}$ & $1.20 \mathrm{~d}-\mathrm{g}$ & $0.0153 a-f$ \\
\hline & $T$ & $8.69 \mathrm{~g}-\mathrm{i}$ & $0.082 \mathrm{de}$ & 17.52 ef & 0.133 e-h & $1.06 \mathrm{~g}$ & $0.0135 d-f$ \\
\hline & $P$ & $8.30 \mathrm{i}$ & $0.081 \mathrm{e}$ & $16.58 \mathrm{f}$ & $0.124 \mathrm{~h}$ & $1.10 \mathrm{fg}$ & 0.0129 ef \\
\hline & $\mathrm{L}$ & $8.85 \mathrm{f}-\mathrm{i}$ & $0.083 \mathrm{c}-\mathrm{e}$ & 17.84 ef & $0.136 d-h$ & $1.10 \mathrm{fg}$ & $0.0138 d-f$ \\
\hline & Z & $8.84 \mathrm{f}-\mathrm{i}$ & $0.083 \mathrm{c}-\mathrm{e}$ & 17.81 ef & $0.136 d-h$ & $1.08 \mathrm{fg}$ & $0.0138 d-f$ \\
\hline & V & $8.94 \mathrm{~d}-\mathrm{i}$ & $0.084 \mathrm{~b}-\mathrm{e}$ & $18.03 d-f$ & $0.138 d-h$ & $1.09 \mathrm{fg}$ & $0.0139 d-f$ \\
\hline & $\mathrm{S}$ & $8.30 \mathrm{i}$ & $0.081 \mathrm{e}$ & $16.93 \mathrm{f}$ & $0.125 \mathrm{~h}$ & $1.06 \mathrm{~g}$ & $0.0124 \mathrm{f}$ \\
\hline & Average & $8.60 \mathrm{~d}$ & $0.083 \mathrm{~d}$ & $17.32 \mathrm{c}$ & $0.134 \mathrm{~d}$ & $1.10 \mathrm{~d}$ & $0.0137 d$ \\
\hline \multirow[t]{8}{*}{ NPK } & $\mathrm{K}$ & 10.60 a-h & 0.098 a-e & $21.53 b-f$ & $0.155 b-h$ & $1.37 \mathrm{a}-\mathrm{g}$ & $0.0169 a-f$ \\
\hline & $T$ & $9.27 \mathrm{~d}-\mathrm{i}$ & 0.092 a-e & $19.42 c-f$ & $0.140 d-h$ & $1.21 \mathrm{~d}-\mathrm{g}$ & $0.0146 b-f$ \\
\hline & $P$ & $8.93 \mathrm{~d}-\mathrm{i}$ & 0.087 a-e & $18.28 d-f$ & $0.132 \mathrm{f}-\mathrm{h}$ & $1.14 \mathrm{~d}-\mathrm{g}$ & $0.0137 d-f$ \\
\hline & L & $9.06 \mathrm{~d}-\mathrm{i}$ & 0.087 a-e & $18.99 d-f$ & $0.137 d-h$ & $1.18 \mathrm{~d}-\mathrm{g}$ & $0.0142 b-f$ \\
\hline & Z & $9.59 c-i$ & 0.093 a-e & $19.63 c-f$ & $0.142 d-h$ & $1.22 \mathrm{~d}-\mathrm{g}$ & $0.0147 a-f$ \\
\hline & V & $10.79 \mathrm{a}-\mathrm{g}$ & 0.103 a-e & 21.66 b-f & 0.156 b-h & $1.35 \mathrm{a}-\mathrm{g}$ & $0.0162 a-f$ \\
\hline & $S$ & 11.10 a-e & 0.099 a-e & 23.04 a-e & $0.155 b-h$ & $1.35 \mathrm{a}-\mathrm{g}$ & $0.0159 a-f$ \\
\hline & Average & $9.91 \mathrm{bc}$ & $0.094 \mathrm{ac}$ & $20.36 \mathrm{~b}$ & $0.145 \mathrm{~cd}$ & $1.26 \mathrm{bc}$ & 0.0152 bc \\
\hline
\end{tabular}


Table 5. Continue.

Çizelge 5. Devamı.

\begin{tabular}{|c|c|c|c|c|c|c|c|}
\hline \multirow[t]{8}{*}{ F1 } & $\mathrm{K}$ & $8.32 \mathrm{i}$ & $0.088 a-e$ & $23.86 \mathrm{a}-\mathrm{d}$ & $0.153 c-h$ & $1.24 \mathrm{cg}$ & $0.0147 a-f$ \\
\hline & $T$ & $8.87 \mathrm{f}-\mathrm{i}$ & 0.086 a-e & 17.71 ef & $0.128 \mathrm{gh}$ & $1.10 \mathrm{fg}$ & 0.0128 ef \\
\hline & $P$ & $8.30 \mathrm{i}$ & 0.088 a-e & $16.72 \mathrm{f}$ & $0.122 \mathrm{~h}$ & $1.07 \mathrm{fg}$ & 0.0129 ef \\
\hline & L & $9.57 c-i$ & 0.093 a-e & $20.57 c-f$ & $0.141 d-h$ & $1.32 \mathrm{a}-\mathrm{g}$ & $0.0147 \mathrm{a}-\mathrm{f}$ \\
\hline & Z & $9.63 c-i$ & 0.093 a-e & $19.70 \mathrm{c}-\mathrm{f}$ & $0.142 d-h$ & $1.22 \mathrm{~d}-\mathrm{g}$ & $0.0148 \mathrm{a}-\mathrm{f}$ \\
\hline & V & 8.52 hi & $0.085 \mathrm{~b}-\mathrm{e}$ & 17.85 ef & $0.129 \mathrm{gh}$ & $1.11 \mathrm{e}-\mathrm{g}$ & $0.0134 d-f$ \\
\hline & $\mathrm{S}$ & $9.55 c-i$ & 0.093 a-e & $21.77 b-f$ & $0.147 \mathrm{~d}-\mathrm{h}$ & $1.12 \mathrm{~d}-\mathrm{g}$ & $0.0135 d-f$ \\
\hline & Average & $8.97 \mathrm{~d}$ & $0.089 \mathrm{~cd}$ & $19.74 \mathrm{~b}$ & $0.137 d$ & $1.17 \mathrm{~cd}$ & $0.0138 \mathrm{~cd}$ \\
\hline \multirow[t]{8}{*}{$\mathrm{F} 2$} & $\mathrm{~K}$ & $8.92 \mathrm{e}-\mathrm{i}$ & $0.081 \mathrm{e}$ & $27.42 \mathrm{a}$ & $0.194 \mathrm{a}$ & $1.30 \mathrm{a}-\mathrm{g}$ & 0.0158 a-f \\
\hline & $T$ & $10.97 \mathrm{a}-\mathrm{f}$ & $0.106 a-c$ & $22.42 \mathrm{a}-\mathrm{f}$ & $0.162 a-h$ & $1.39 \mathrm{a}-\mathrm{g}$ & $0.0168 \mathrm{a}-\mathrm{f}$ \\
\hline & $P$ & $9.20 \mathrm{~d}-\mathrm{i}$ & 0.089 a-e & $18.83 d-f$ & $0.136 d-h$ & $1.17 \mathrm{~d}-\mathrm{g}$ & $0.0141 c-f$ \\
\hline & L & $10.84 \mathrm{a}-\mathrm{g}$ & 0.105 a-e & $22.19 a-f$ & 0.160 a-h & $1.38 \mathrm{a}-\mathrm{g}$ & 0.0166 a-f \\
\hline & Z & $8.98 d-i$ & 0.091 a-e & $19.24 d-f$ & $0.139 d-h$ & $1.20 \mathrm{~d}-\mathrm{g}$ & $0.0144 b-f$ \\
\hline & V & 8.56 hi & $0.081 \mathrm{e}$ & $16.57 \mathrm{f}$ & $0.124 \mathrm{~h}$ & $1.06 \mathrm{~g}$ & $0.0125 \mathrm{f}$ \\
\hline & $\mathrm{S}$ & $9.83 \mathrm{~b}-\mathrm{i}$ & 0.095 a-e & $20.12 c-f$ & $0.145 d-h$ & $1.25 \mathrm{c}-\mathrm{g}$ & $0.0151 \mathrm{a}-\mathrm{f}$ \\
\hline & Average & $9.61 \mathrm{c}$ & 0.093 bc & $20.97 \mathrm{ab}$ & 0.151 bc & $1.25 \mathrm{bc}$ & $0.0151 \mathrm{bd}$ \\
\hline \multirow[t]{8}{*}{ F3 } & $\mathrm{K}$ & $10.39 \mathrm{~b}-\mathrm{i}$ & 0.095 a-e & $20.35 c-f$ & $0.147 \mathrm{~d}-\mathrm{h}$ & $1.26 \mathrm{~b}-\mathrm{g}$ & 0.0153 a-f \\
\hline & $\mathrm{T}$ & $10.59 a-h$ & 0.101 a-e & $21.67 \mathrm{~b}-\mathrm{f}$ & 0.156 b-h & $1.35 \mathrm{a}-\mathrm{g}$ & 0.0162 a-f \\
\hline & $P$ & $10.60 a-h$ & 0.100 a-e & $21.12 b-f$ & $0.152 c-h$ & $1.31 \mathrm{a}-\mathrm{g}$ & $0.0158 \mathrm{a}-\mathrm{f}$ \\
\hline & L & $12.51 \mathrm{a}$ & $0.109 a b$ & 23.38 a-e & $0.171 \mathrm{a}-\mathrm{f}$ & $1.45 a-f$ & 0.0175 a-e \\
\hline & Z & $9.41 \mathrm{~d}-\mathrm{i}$ & 0.091 a-e & $19.26 d-f$ & $0.139 d-h$ & $1.20 \mathrm{~d}-\mathrm{g}$ & $0.0144 b-f$ \\
\hline & V & $10.34 b-i$ & 0.100 a-e & $21.17 b-f$ & $0.153 c-h$ & $1.32 \mathrm{a}-\mathrm{g}$ & $0.0159 \mathrm{a}-\mathrm{f}$ \\
\hline & $S$ & $11.80 \mathrm{ab}$ & $0.110 \mathrm{a}$ & $23.84 a-d$ & $0.174 a-d$ & $1.50 \mathrm{a}-\mathrm{d}$ & $0.0181 \mathrm{a}-\mathrm{d}$ \\
\hline & Average & $10.81 \mathrm{a}$ & 0.101 a & $21.54 \mathrm{ab}$ & 0.156 ac & $1.34 \mathrm{ab}$ & $0.0162 \mathrm{ab}$ \\
\hline \multirow[t]{8}{*}{ F4 } & $\mathrm{K}$ & $12.56 \mathrm{a}$ & 0.102 a-e & $27.42 \mathrm{a}$ & $0.195 \mathrm{a}$ & $1.64 \mathrm{a}$ & $0.0188 \mathrm{a}-\mathrm{c}$ \\
\hline & $\mathrm{T}$ & $10.62 a-h$ & 0.102 a-e & $21.55 b-f$ & 0.155 b-h & $1.34 \mathrm{a}-\mathrm{g}$ & 0.0162 a-f \\
\hline & $P$ & 8.91 ei & 0.086 a-e & $18.23 d-f$ & $0.132 \mathrm{f}-\mathrm{h}$ & $1.13 \mathrm{~d}-\mathrm{g}$ & $0.0137 d-f$ \\
\hline & L & $10.56 a-h$ & 0.104 a-e & $22.02 a-f$ & 0.160 a-h & $1.37 \mathrm{a}-\mathrm{g}$ & 0.0165 a-f \\
\hline & Z & $10.95 a-f$ & $0.106 \mathrm{a}-\mathrm{d}$ & $22.36 \mathrm{a}-\mathrm{f}$ & 0.161 a-h & $1.39 \mathrm{a}-\mathrm{g}$ & $0.0168 \mathrm{a}-\mathrm{f}$ \\
\hline & V & $11.13 \mathrm{a}-\mathrm{d}$ & $0.108 a b$ & 23.08 a-e & 0.160 a-h & $1.42 \mathrm{a}-\mathrm{g}$ & 0.0171 a-f \\
\hline & $\mathrm{S}$ & $10.84 \mathrm{a}-\mathrm{g}$ & 0.101 a-e & $25.11 \mathrm{a}-\mathrm{c}$ & 0.190 a-c & $1.60 \mathrm{a}-\mathrm{c}$ & $0.0190 \mathrm{ab}$ \\
\hline & Average & 10.80 a & 0.101 a & 22.82 a & 0.165 a & $1.41 \mathrm{a}$ & 0.0169 a \\
\hline \multirow[t]{8}{*}{ F5 } & $\mathrm{K}$ & $9.07 \mathrm{~d}-\mathrm{i}$ & 0.089 a-e & $27.46 \mathrm{a}$ & $0.190 \mathrm{a}-\mathrm{c}$ & $1.50 \mathrm{a}-\mathrm{d}$ & $0.0189 a b$ \\
\hline & $T$ & $9.23 \mathrm{~d}-\mathrm{i}$ & 0.089 a-e & $18.68 d-f$ & $0.135 d-h$ & $1.16 \mathrm{~d}-\mathrm{g}$ & $0.0140 \mathrm{~d}-\mathrm{f}$ \\
\hline & $P$ & 9.88 b-i & 0.089 a-e & $18,46 d-f$ & 0.133 e-h & $1.15 \mathrm{~d}-\mathrm{g}$ & $0.0138 d-f$ \\
\hline & L & $12.56 \mathrm{a}$ & $0.110 a$ & $26.54 a-b$ & $0.192 \mathrm{ab}$ & 1.65 a & 0.0194 a \\
\hline & Z & 10.36 b-i & 0.105 a-e & $20.76 c-f$ & $0.150 \mathrm{~d}-\mathrm{h}$ & $1.29 \mathrm{a}-\mathrm{g}$ & $0.0156 a-f$ \\
\hline & V & $11.62 \mathrm{a}-\mathrm{c}$ & $0.110 \mathrm{a}$ & $23.88 \mathrm{a}-\mathrm{d}$ & 0.172 a-e & 1.48 a-e & $0.0181 \mathrm{a}-\mathrm{d}$ \\
\hline & $\mathrm{S}$ & $10.96 a-f$ & 0.097 a-e & $20.63 c-f$ & $0.149 \mathrm{~d}-\mathrm{h}$ & $1.34 \mathrm{a}-\mathrm{g}$ & $0.0156 a-f$ \\
\hline & Average & $10.53 \mathrm{ab}$ & $0.098 \mathrm{ab}$ & 22.35 a & $0.160 \mathrm{ab}$ & $1.37 \mathrm{ab}$ & $0.0165 \mathrm{ab}$ \\
\hline Biological & $\mathrm{K}$ & $8.34 \mathrm{i}$ & 0.099 a-e & $17.03 \mathrm{f}$ & 0.146 d-h & $1.63 \mathrm{ab}$ & $0.0189 a-c$ \\
\hline \multirow[t]{7}{*}{ Fertilizer } & $T$ & $9.13 \mathrm{~d}-\mathrm{i}$ & 0.088 a-e & $19.21 \mathrm{~d}-\mathrm{f}$ & $0.139 d-h$ & $1.19 \mathrm{~d}-\mathrm{g}$ & $0.0144 b-f$ \\
\hline & $P$ & 10.93 a-f & 0.105 a-e & 23.00 a-e & $0.166 \mathrm{a}-\mathrm{g}$ & $1.43 \mathrm{a}-\mathrm{g}$ & $0.0172 \mathrm{a}-\mathrm{f}$ \\
\hline & L & $11.01 \mathrm{a}-\mathrm{f}$ & $0.106 \mathrm{a}-\mathrm{d}$ & 23.17 a-e & $0.167 \mathrm{a}-\mathrm{g}$ & $1.44 \mathrm{a}-\mathrm{g}$ & 0.0174 a-e \\
\hline & Z & $9.45 \mathrm{~d}-\mathrm{i}$ & 0.091 a-e & $19.90 c-f$ & $0.144 d-h$ & $1.24 \mathrm{c}-\mathrm{g}$ & $0.0149 \mathrm{a}-\mathrm{f}$ \\
\hline & V & 10.04 b-i & 0.097 a-e & $21.14 b-f$ & $0.153 c-h$ & $1.31 \mathrm{a}-\mathrm{g}$ & $0.0159 \mathrm{a}-\mathrm{f}$ \\
\hline & $S$ & $10.37 \mathrm{~b}-\mathrm{i}$ & 0.100 a-e & $19.66 c-f$ & $0.147 d-h$ & $1.36 \mathrm{a}-\mathrm{g}$ & $0.0164 \mathrm{a}-\mathrm{f}$ \\
\hline & Average & 9.89 bc & $0.098 \mathrm{ab}$ & $20.45 \mathrm{~b}$ & 0.152 bc & $1.37 \mathrm{ab}$ & $0.0164 \mathrm{ab}$ \\
\hline Treatment & $\mathrm{K}$ & $9.56 \mathrm{~b}$ & $0.092 a b$ & $22.70 \mathrm{a}$ & $0.165 \mathrm{a}$ & $1.39 \mathrm{a}$ & 0.0168 a \\
\hline \multirow[t]{6}{*}{ Average } & $T$ & $9.67 \mathrm{~b}$ & $0.093 a b$ & $19.77 \mathrm{~cd}$ & $0.143 \mathrm{~cd}$ & $1.23 \mathrm{~cd}$ & $0.0148 \mathrm{~cd}$ \\
\hline & $P$ & $9.38 \mathrm{~b}$ & $0.091 \mathrm{~b}$ & $18.90 \mathrm{~d}$ & $0.137 \mathrm{~d}$ & $1.19 \mathrm{~d}$ & $0.0143 \mathrm{~d}$ \\
\hline & L & $10.62 \mathrm{a}$ & $0.100 \mathrm{a}$ & $21.84 a b$ & $0.158 \mathrm{ab}$ & $1.36 a b$ & $0.0163 a b$ \\
\hline & Z & 9.65 b & $0.094 a b$ & $19.83 \mathrm{~cd}$ & $0.144 \mathrm{~cd}$ & $1.23 \mathrm{~cd}$ & $0.0149 \mathrm{~b}-\mathrm{d}$ \\
\hline & V & $9.99 a b$ & $0.096 \mathrm{ab}$ & $20.42 b-d$ & $0.148 b-d$ & $1.27 \mathrm{~b}-\mathrm{d}$ & $0.0154 \mathrm{~b}-\mathrm{d}$ \\
\hline & $\mathrm{S}$ & $10.34 \mathrm{a}$ & $0.097 \mathrm{ab}$ & $21.39 a-c$ & $0.154 a-c$ & $1.32 \mathrm{a}-\mathrm{c}$ & $0.0157 \mathrm{a}-\mathrm{c}$ \\
\hline
\end{tabular}

*The differences between the means indicated with the same letter are not significant $(p<0.05)$ in their group. 
Table 6. The effect of different carriers, bacterial combinations and fertilizer application on alcohol dehydrogenase and 5dehydroxyshikimate reductase enzyme activity in Pazar-20 tea clone (2015).

Çizelge 6. Farklı taşıyıcı, bakteri kombinasyonları ve gübre uygulamasının Pazar-20 çay klonunda alkol dehidrogenaz ve 5dehidroksişikimat redüktaz enzim aktivitesi üzerine etkisi (2015).

\begin{tabular}{|c|c|c|c|c|c|}
\hline \multirow[b]{2}{*}{ Treatment } & \multirow[b]{2}{*}{ Carrier } & \multicolumn{2}{|c|}{ Alchol dehidrogenase } & \multicolumn{2}{|c|}{ 5-Dehydroksişikimat redüktase } \\
\hline & & $\left(\right.$ EU g leaf $\left.{ }^{-1}\right) *$ & $\left(\right.$ EU mg protein $\left.{ }^{-1}\right)$ & $\left(\right.$ EU g leaf $\left.{ }^{-1}\right)$ & $\left(\right.$ EU mg protein $\left.{ }^{-1}\right)$ \\
\hline \multirow[t]{7}{*}{ Control } & $\mathrm{K}$ & 1.54 a-d & $0.052 \mathrm{a}-\mathrm{c}$ & $2.73 \mathrm{c}-\mathrm{f}$ & $0.040 \mathrm{~d}$ \\
\hline & $\mathrm{T}$ & $1.30 \mathrm{a}-\mathrm{g}$ & $0.045 a-f$ & $2.62 \mathrm{~d}-\mathrm{f}$ & $0.070 \mathrm{~cd}$ \\
\hline & $\mathrm{P}$ & $1.24 \mathrm{bg}$ & $0.043 a-f$ & 2.46 ef & $0.085 a-d$ \\
\hline & L & $1.41 \mathrm{a}-\mathrm{f}$ & $0.045 a-f$ & $2.67 c-f$ & $0.067 \mathrm{~cd}$ \\
\hline & Z & 1.50 a-e & $0.047 a-f$ & $2.60 \mathrm{~d}-\mathrm{f}$ & $0.073 \mathrm{~cd}$ \\
\hline & V & $1.43 \mathrm{a}-\mathrm{f}$ & $0.053 \mathrm{ab}$ & $2.70 c-f$ & $0.094 \mathrm{a}-\mathrm{c}$ \\
\hline & $\mathrm{S}$ & $1.31 \mathrm{a}-\mathrm{g}$ & $0.044 a-f$ & $2.37 \mathrm{f}$ & $0.039 \mathrm{~d}$ \\
\hline \multicolumn{2}{|c|}{ Average } & $1.39 \mathrm{~b}$ & $0.047 \mathrm{~b}$ & $2.59 \mathrm{c}$ & $0.067 \mathrm{c}$ \\
\hline \multirow[t]{8}{*}{ NPK } & $\mathrm{K}$ & $1.38 \mathrm{a}-\mathrm{g}$ & $0.050 \mathrm{a}-\mathrm{d}$ & $3.01 a-f$ & $0.095 a-c$ \\
\hline & $\mathrm{T}$ & 1.28 a-g & $0.047 a-f$ & $2.58 \mathrm{~d}-\mathrm{f}$ & $0.083 a-d$ \\
\hline & $P$ & $1.16 \mathrm{fg}$ & 0.036 ef & $2.43 \mathrm{f}$ & $0.078 b-d$ \\
\hline & L & $1.22 \mathrm{c}-\mathrm{g}$ & $0.045 a-f$ & 2.53 ef & $0.081 \mathrm{a}-\mathrm{d}$ \\
\hline & Z & $1.24 \mathrm{~b}-\mathrm{g}$ & 0.046 a-f & $2.61 \mathrm{~d}-\mathrm{f}$ & $0.084 a-d$ \\
\hline & V & $1.32 \mathrm{a}-\mathrm{g}$ & $0.048 a-f$ & $2.88 b-f$ & $0.093 a-c$ \\
\hline & $S$ & $1.29 \mathrm{a}-\mathrm{g}$ & 0.046 a-f & $3.37 \mathrm{a}-\mathrm{c}$ & $0.101 \mathrm{a}-\mathrm{c}$ \\
\hline & & $1.27 \mathrm{c}$ & $0.046 \mathrm{~b}$ & 2.77 bc & $0.088 \mathrm{ab}$ \\
\hline \multirow[t]{8}{*}{ F1 } & $\mathrm{K}$ & $1.06 \mathrm{~g}$ & $0.035 \mathrm{f}$ & $2.85 b-f$ & $0.115 a-c$ \\
\hline & $\mathrm{T}$ & $1.06 \mathrm{~g}$ & $0.045 a-f$ & $2.36 \mathrm{f}$ & $0.076 \mathrm{~b}-\mathrm{d}$ \\
\hline & $P$ & $1.17 \mathrm{e}-\mathrm{g}$ & $0.035 \mathrm{f}$ & $2.36 \mathrm{f}$ & $0.071 \mathrm{~cd}$ \\
\hline & L & $1.08 \mathrm{~g}$ & $0.039 c-f$ & $2.60 \mathrm{~d}-\mathrm{f}$ & $0.084 a-d$ \\
\hline & Z & $1.07 \mathrm{~g}$ & $0.038 d-f$ & $2.62 \mathrm{~d}-\mathrm{f}$ & $0.084 a-d$ \\
\hline & V & $1.07 \mathrm{~g}$ & 0.036 ef & $2.37 \mathrm{f}$ & $0.076 \mathrm{~b}-\mathrm{d}$ \\
\hline & $S$ & $1.23 \mathrm{c}-\mathrm{g}$ & 0.036 ef & $2.89 b-f$ & 0.088 a-c \\
\hline & & $1.10 \mathrm{~d}$ & $0.038 \mathrm{c}$ & $2.58 \mathrm{c}$ & $0.085 \mathrm{~b}$ \\
\hline \multirow[t]{8}{*}{ F2 } & $\mathrm{K}$ & 1.53 a-d & $0.056 \mathrm{ab}$ & 3.27 a-d & $0.115 \mathrm{a}-\mathrm{c}$ \\
\hline & $\mathrm{T}$ & $1.31 \mathrm{a}-\mathrm{g}$ & $0.046 a-f$ & 2.98 a-f & $0.096 a-c$ \\
\hline & $P$ & $1.20 \mathrm{~d}-\mathrm{g}$ & $0.042 b-f$ & 2.50 ef & $0.081 \mathrm{a}-\mathrm{d}$ \\
\hline & L & $1.38 \mathrm{a}-\mathrm{g}$ & $0.048 a-f$ & $2.95 b-f$ & $0.095 a-c$ \\
\hline & Z & $1.31 \mathrm{a}-\mathrm{g}$ & $0.046 a-f$ & $2.56 \mathrm{~d}-\mathrm{f}$ & $0.082 \mathrm{a}-\mathrm{d}$ \\
\hline & V & $1.20 \mathrm{~d}-\mathrm{g}$ & $0.043 a-f$ & $2.38 \mathrm{f}$ & $0.074 b-d$ \\
\hline & $S$ & $1.31 \mathrm{a}-\mathrm{g}$ & 0.046 a-f & $2.68 c-f$ & $0.086 \mathrm{a}-\mathrm{d}$ \\
\hline & & $1.32 \mathrm{bc}$ & $0.047 \mathrm{~b}$ & 2.76 bc & $0.090 \mathrm{ab}$ \\
\hline \multirow[t]{8}{*}{ F3 } & $\mathrm{K}$ & $1.37 \mathrm{a}-\mathrm{g}$ & 0.049 a-e & $2.71 c-f$ & $0.087 a-c$ \\
\hline & $\mathrm{T}$ & $1.34 \mathrm{a}-\mathrm{g}$ & $0.048 \mathrm{a}-\mathrm{f}$ & $2.88 b-f$ & 0.093 a-c \\
\hline & $P$ & $1.26 \mathrm{~b}-\mathrm{g}$ & $0.045 a-f$ & $2.81 c-f$ & $0.090 a-c$ \\
\hline & L & $1.38 \mathrm{a}-\mathrm{g}$ & 0.049 a-e & 3.18 a-e & $0.103 \mathrm{a}-\mathrm{c}$ \\
\hline & Z & $1.28 \mathrm{a}-\mathrm{g}$ & $0.046 a-f$ & $2.56 \mathrm{~d}-\mathrm{f}$ & $0.083 a-d$ \\
\hline & V & $1.23 \mathrm{c}-\mathrm{g}$ & $0.044 a-f$ & $2.82 c-f$ & $0.091 \mathrm{a}-\mathrm{c}$ \\
\hline & $S$ & $1.31 \mathrm{a}-\mathrm{g}$ & $0.047 a-f$ & 3.26 a-d & $0.106 a-c$ \\
\hline & & $1.31 \mathrm{bc}$ & 0.047 b & $2.89 \mathrm{ab}$ & $0.093 a b$ \\
\hline \multirow[t]{8}{*}{ F4 } & $\mathrm{K}$ & $1.56 a-c$ & $0.051 \mathrm{a}-\mathrm{d}$ & 3.66 a & 0.128 a \\
\hline & $\mathrm{T}$ & $1.49 a-f$ & 0.049 a-e & $2.87 \mathrm{~b}-\mathrm{f}$ & $0.092 a-c$ \\
\hline & $\mathrm{P}$ & $1.33 \mathrm{a}-\mathrm{g}$ & $0.044 a-f$ & $2.42 \mathrm{f}$ & $0.096 a-c$ \\
\hline & L & $1.56 a-c$ & $0.051 \mathrm{a}-\mathrm{d}$ & $2.93 b-f$ & $0.103 a-c$ \\
\hline & Z & $1.52 \mathrm{a}-\mathrm{d}$ & 0.050 a-d & $2.97 b-f$ & $0.096 a-c$ \\
\hline & V & 1.48 a-f & $0.048 a-f$ & $3.06 a-f$ & $0.098 a-c$ \\
\hline & $S$ & $1.58 \mathrm{ab}$ & $0.052 \mathrm{ac}$ & $3.35 a-c$ & $0.108 \mathrm{a}-\mathrm{c}$ \\
\hline & & 1.50 a & $0.049 a b$ & $3.04 \mathrm{a}$ & 0.103 a \\
\hline \multirow[t]{7}{*}{ F5 } & $\mathrm{K}$ & $1.60 \mathrm{a}$ & $0.056 \mathrm{a}$ & $3.66 a$ & $0.122 \mathrm{ab}$ \\
\hline & $\mathrm{T}$ & $1.48 a-f$ & 0.050 a-d & 2.48 ef & $0.080 \mathrm{a}-\mathrm{d}$ \\
\hline & $P$ & $1.34 \mathrm{a}-\mathrm{g}$ & $0.046 a-f$ & 2.46 ef & $0.099 a-c$ \\
\hline & L & $1.61 \mathrm{a}$ & 0.056 a & $3.53 a b$ & $0.114 a-c$ \\
\hline & Z & $1.46 \mathrm{a}-\mathrm{f}$ & 0.050 a-d & $2.76 c-f$ & $0.089 a-c$ \\
\hline & V & 1.51 a-e & $0.052 a-c$ & 3.18 a-e & $0.102 a-c$ \\
\hline & $S$ & $1.44 \mathrm{a}-\mathrm{f}$ & 0.049 a-e & $2.78 c-f$ & $0.090 \mathrm{a}-\mathrm{c}$ \\
\hline
\end{tabular}




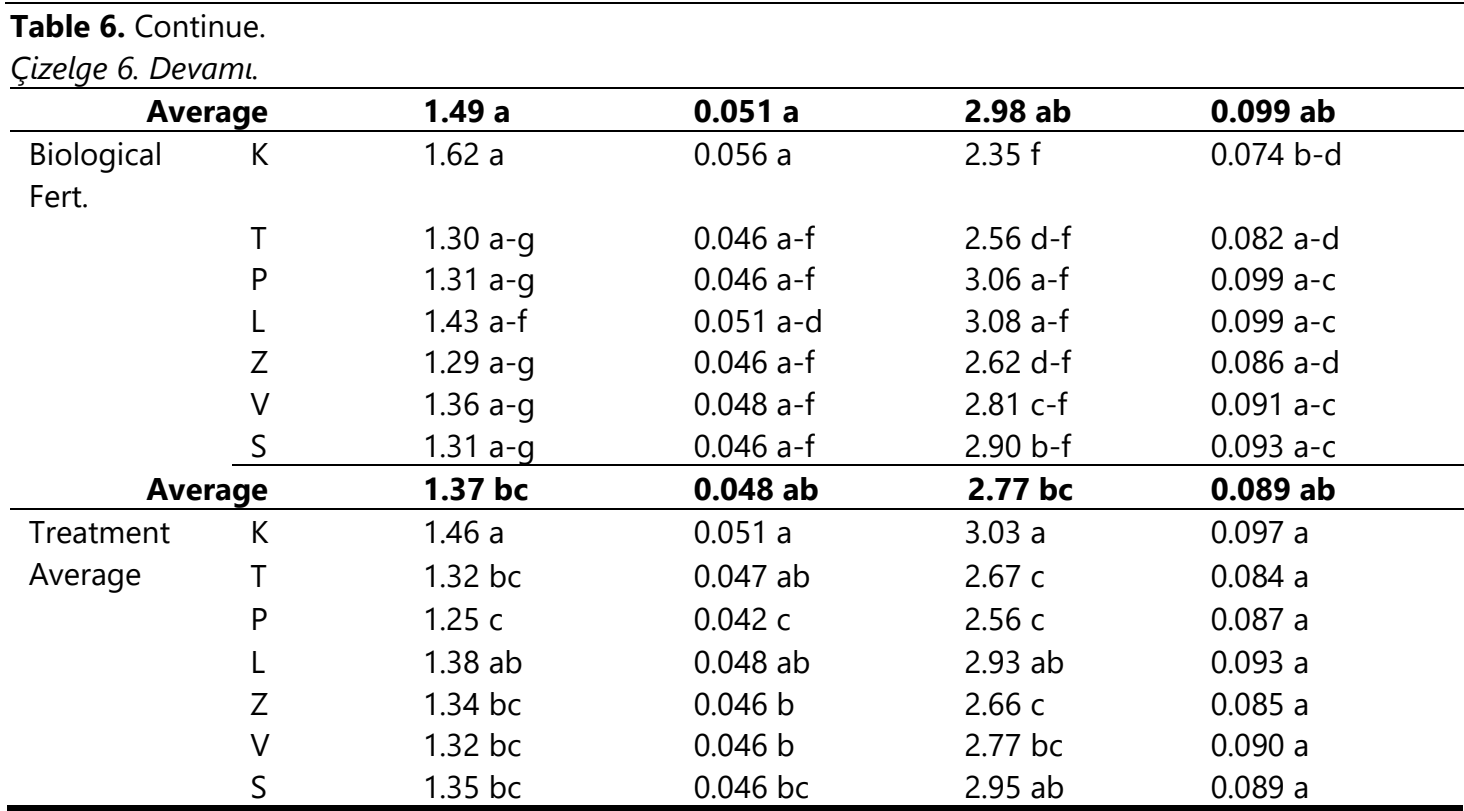

${ }^{*}$ The differences between the means indicated with the same letter are not significant $(p<0.05)$ in their group.

Table 7. The effect of different carriers, bacterial combinations and mineral fertilizer application on leaf GR, GST, G6PD and 6PGD enzyme activity in Pazar-20 tea clone (2015).

Çizelge 7. Farklı taşıyıcı, bakteri kombinasyonları ve mineral gübre uygulamasının Pazar-20 çay klonunda yaprak GR, GST, G6PD ve 6PGD enzim aktivitesi üzerine etkisi (2015).

\begin{tabular}{lllll}
\hline Variation & \multicolumn{4}{c}{ Enzym activity EU mg protein ${ }^{-1}$} \\
\cline { 2 - 5 } Sources & GR & GST & G6PD & 6 PGD \\
\hline Control & $1.65 \mathrm{e}$ & $1.41 \mathrm{~d}$ & $1.72 \mathrm{e}$ & $1.18 \mathrm{~d}$ \\
NPK & $2.87 \mathrm{~b}$ & $2.55 \mathrm{ab}$ & $1.86 \mathrm{~d}$ & $1.64 \mathrm{c}$ \\
FI & $2.61 \mathrm{c}$ & $2.45 \mathrm{~b}$ & $2.03 \mathrm{c}$ & $1.72 \mathrm{~b}$ \\
F2 & $2.40 \mathrm{~d}$ & $2.31 \mathrm{c}$ & $2.10 \mathrm{bc}$ & $1.63 \mathrm{c}$ \\
F3 & $2.45 \mathrm{~d}$ & $2.54 \mathrm{ab}$ & $2.57 \mathrm{a}$ & $1.93 \mathrm{a}$ \\
F4 & $2.54 \mathrm{~cd}$ & $2.21 \mathrm{c}$ & $2.20 \mathrm{~b}$ & $1.76 \mathrm{~b}$ \\
F5 & $2.42 \mathrm{~d}$ & $2.27 \mathrm{c}$ & $2.07 \mathrm{c}$ & $1.87 \mathrm{a}$ \\
Biological Fertilizer & $3.04 \mathrm{a}$ & $2.65 \mathrm{a}$ & $1.96 \mathrm{~cd}$ & $1.89 \mathrm{a}$ \\
\hline & & Carriers $(\mathrm{n}=32)$ & \\
\hline Compost & $2.50 \mathrm{bc}$ & $2.35 \mathrm{~b}$ & $2.00 \mathrm{bc}$ & $1.70 \mathrm{a}$ \\
Peat & $2.44 \mathrm{~cd}$ & $2.50 \mathrm{a}$ & $1.95 \mathrm{c}$ & $1.76 \mathrm{a}$ \\
Perlite & $2.32 \mathrm{~d}$ & $2.21 \mathrm{c}$ & $2.06 \mathrm{a}-\mathrm{c}$ & $1.56 \mathrm{~b}$ \\
Leonardite & $2.50 \mathrm{bc}$ & $2.29 \mathrm{bc}$ & $2.07 \mathrm{a}-\mathrm{c}$ & $1.70 \mathrm{a}$ \\
Zeolite & $2.45 \mathrm{c}$ & $2.28 \mathrm{bc}$ & $2.13 \mathrm{a}$ & $1.75 \mathrm{a}$ \\
Vermiculite & $2.59 \mathrm{ab}$ & $2.18 \mathrm{c}$ & $2.09 \mathrm{ab}$ & $1.71 \mathrm{a}$ \\
Liquid formula & $2.69 \mathrm{a}$ & $2.28 \mathrm{bc}$ & $2.16 \mathrm{a}$ & $1.73 \mathrm{a}$ \\
\hline
\end{tabular}

*The differences between the means indicated with the same letter are not significant $(p<0.05)$ in their group.

The values related to the effects of the applications on the enzyme activity of the leaves in the seedlings of the Pazar-20 tea clone are given in Table 7. While GR, GST, G6PD, and 6PGD activities gave the highest values especially in the $\mathrm{F} 3$ formulation, the application of biological fertilizers also increased the enzyme activity significantly. All of the bacterial formulations increased leaf enzyme activity compared to the control. In terms of different carriers used to commercialize bacterial formulations, the liquid carrier gave the best values in terms of the effect on leaf enzyme values. While peat was the best carrier for GST and 6PGD enzymes, zeolite carrier gave the highest values for G6PD and 6PGD enzymes (Table 7). F4, F3, and F5 formulations provided the highest leaf PPO, POD, and urease values in 2015, respectively. In the same year, F4, F5, and F3 rankings were valid in terms of Alcohol Dehydrogenase and 5-Dehydroxyshikimate enzyme values (Tables 5 and 6). In terms of carriers, the efficiency of different enzyme activities was determined in the same year, especially in carriers such as liquid formula and peat (Table 7). 


\section{CONCLUSION}

The regular continuation of the chemical reactions taking place in the cells is with the help of the enzymes in the cell, and the complex molecules are broken down into simple molecules by the effect of the enzymes. The enzymes found in the young leaves and shoots of the tea plant create biochemical transformations during the processing stage, giving the tea its characteristic taste and smell. The production of different types and qualities of black tea occurs thanks to the enzymes in the young tea leaves and buds. Especially oxidative enzymes serve in the production of black tea. In addition, some of the enzymes discussed are those that have direct or indirect effects on the development of the plant's resistance to stress factors (Savanakumar et al., 2007; Mishra et al., 2014).

In many studies conducted in similar ecology, as in this study, it has been determined that there is a close relationship between the enzyme activities in plant leaves and the growing support of the PGPR isolates used (Çakmakçı, 2016; Çakmakçı et al., 2017). Also, the changes in enzyme activities are affected differently by the bacterial isolates and carriers in the formulas used. Therefore, it is expected that there will be increased in many growth parameters with PGPR applications of enzymes responsible for both the quality of the finished tea and many growth reactions (enzymes are also active in nitrate assimilation). However; failures in these applications may be due to the inability to select the appropriate bacterial association a combination of carriers. That's why; many studies are needed to determine the activities of PGPRs in the tea rhizosphere. In the future, studies to determine the effects of PGPR strains on different enzyme activities will contribute to the search for alternatives that can provide efficacy against biotic and abiotic stress conditions encountered in tea cultivation. The effect of the tested isolates on the enzymes in plant leaves can be explained by the interaction of plant $\mathrm{X}$ microorganism $X$ carrier in a particular plant environment in particular ecology, as well as the classical mechanism of action. Although the effectiveness of the fertilizer dose used in the studies disappears after a period of time, it is reported that the bacterial activity (although it varies depending on many factors) may be longer and permanent (Ramkumar et al., 2015; Çakmakçı, 2016; Çakmakçı et al., 2011 and 2017; Ertürk et al., 2011 and 2014).

The use of effective bacteria with multiple characteristics, such as the bacterial isolates used in this research, may ultimately contribute to reducing the environmental pollution. In short, it is a very important and expected result that soils inoculated with PGPRs have a higher yield potential.

\section{CONFLICT OF INTEREST}

There is no conflict of interest between the authors

\section{DECLARATION OF AUTHOR CONTRIBUTION}

Yaşar ERTÜRK; Planning, field studies, evaluation, writing

Ramazan Çakmakçı́; Planning, field studies, statical analysis, evaluation,

Meral KUTLU; Field studies

\section{ACKNOWLEDGMENT}

This work is financially supported by the Scientific and Technological Research Council of Turkey (TOVAG; 112 O 313 project).

\section{REFERENCES}

Angelini, R., Manes, F., \& Federico, R. (1990). Spatial and functional correlation between diamine-oxidase and peroxidase activities and their dependence upon deetiolation and wounding in chick-pea stems. Planta, 182, 89-96.

Beutler, E. (1984). Red cell metabolism. Manual of biochemical methods. Third edition, Grune Stratton, Inc. Orlando, FL 32887, London.

Bhattacharyya, C., Banerjee, S., Acharya, U., Mitra, A., Mallick, I., Haldar, A., Haldar, S., Ghosh, A., \& Ghosh, A. (2020). Evaluation of plant growth promotion properties and induction of antioxidative defense mechanism by tea rhizobacteria of Darjeeling, India. Scientific Reports 10,15536.

Bradford, M. M. (1976). A rapid and sensitive method for the quantitation of microgram quantities of protein utilizing the principle of protein-dye binding. Analytical Biochemistry, 72, 248-251. 
Ertürk et al., Effects of Different Biological Fertilizers Formulated With Multiple Bacteria and Carriers in Pazar 20 Tea Clones on Leaf Enzyme Activity

Carlberg, I., \& Mannervik, B. (1985). Glutathione reductase assay. In Methods in Enzymol, FL. 113, 484-495. Orlando, Academic Press.

Chakraborty, U., Chakraborty, B. N., Basnet, M., \& Chakraborty, A. P. (2009). Evaluation of Ochrobactrum anthropi TRS-2 and its talc based formulation for enhancement of growth of tea plants and management of brown root rot disease. Journal Applied Microbiology 107, 625-634.

Chakraborty, A. P. C., \& Chakraborty, U. (2015). Bacillus megaterium from tea rhizosphere promotes growth and induces systemic resistance in tea against Sclerotium rolfsii. Indian Phytopathology 68, 237-247.

Cernava, T., Chen, X., Krug, L., Li, H., Yang, M., \& Berg, G. (2019). Tea leaf microbiome shows specifc responses to chemical pesticides and biocontrol applications. Science Total Environment, 667, 33-40.

Cakmakci, R., Donmez, M. F., Erturk, Y., Erat, M., Haznedar, A., \& Sekban, R. (2010). Diversity and metabolic potential of culturable bacteria from the rhizosphere of Turkish tea grown in acidic soils. Plant and Soil, 332, 299-318.

Çakmakçı, R., Ertürk, Y., Atasever, A., Ercişli, S., Şentürk, M., Erat, M., Haznedar, A., \& Sekban, R. (2011). The use of plant growth promoting rhizobacteria for organic tea production in Turkey. Proceedings of Tea-Organic-Low Carbon International Symposium, 89-97, 6-9 June, 2011, Guangyuan/China.

Çakmakçı, R. (2016). Screening of multi-trait rhizobacteria for Improving the growth, enzyme activities, and nutrient uptake of tea (Camellia sinensis). Communications in Soil Science and Plant Analysis, 47(13-14), 1680-1690.

Çakmakçı, R., Ertürk, Y., Varmazyari, A., Atasever, A., Kotan R., Haliloğlu, K., Erat M., Türkyılmaz K., Sekban R., \& Haznedar A. (2017). The effect of bacteria-based formulations on tea (Camellia sinensis L.) growth, yield, and enzyme activities. Annals of Warsaw University of Life Sciences - SGGW, Horticulture and Landscape Architecture, 38, 5-18.

Cakmakçı, R. (2019). The variability of the predominant culturable plant growth promoting rhizobacterial diversity in the acidic tea rhizosphere soils in the Eastern Black Sea Region. Alinteri Journal of Agricultural Science 34 (2), 175-181.

Çalıkoğlu, E., \& Bayrak, A. (2009). Çay işleme sırasında aroma maddelerindeki değişim. Gıda, 34 (2), 115-119.

Dutta, J., Handique, P. J., \& Takur, D. (2015). Assessment of culturable tea rhizobacteria isolated from tea estates of assam, india for growth promotion in commercial tea cultivars. Frontiers Microbiology, 6, 1252.

Ertürk Y., Ercisli S., Sengül M., Eser Z., Haznedar A., \& Turan M. (2010). Seasonal variation of total phenolic antioxidant activity and minerals in fresh tea shoots Camellia sinensis var Sinensis. Pakistan Journal of Pharmaceutical Sciences, 23 (1), $69-74$.

Ertürk, Y., Çakmakçı, R., Dönmez, M. F., Sekban R., \& Haznedar A. (2011). Doğu Karadeniz Bölgesi asidik topraklarından izole edilmiş bazı bitki büyümesini teşvik edici rizobakterilerin (PGPR) çay bitkisinin fidan gelişimi aşamasında kullanım olanaklarının araştırılması. Türkiye VI. Ulusal Bahçe Bitkileri Kongresi, Şanlıurfa.

Ertürk Y., Çakmakçı Y., Sekban R., \& Haznedar A. (2014). Biological fertilizer researches for organic tea culture in Turkey (Period: 2007- 2013). International Mesopotamia Agriculture Congress, Diyarbakır, Turkey.

Habig, W. H., Pabst, M. J., \& Jakoby, W. B. (1974). Glutathione S-transferase: the first enzymalic step in mercaptric acid formation. Journal of Biological Chemistry, 249, 7130-7139.

Hatanaka, A., Kajivara, T., Tomohiro, S., \& Yamashita, H. (1974). Alcohol dehydrogenase from Thea sinensis seeds. Agricultural and Biological Chemistry, 38(10), 1835-1844.

Kacar, B. (2010). Çay Bitkisi Biyokimyası, Gübrelenmesi, İşlenme Teknolojisi. Nobel Yayın No: 1549.

Lee, P. M., Lee, K., \& Karim, M. I. A. (1991). Biochemical studies of cocoa bean polyphenol oxidase. Journal of the Science and Food Agriculture, 55, 251-260.

Mei, X., Lin, D. H., Xu, Y., Wu, Y. Y., You-Ying Tu, Y. Y. (2009). Effects of phenanthrene on chemical composition and enzyme activity in fresh tea leaves. Food Food Chemistry, 115, $569-573$.

Mishra, A. K., Morang, P., Deka, M., Nishanth Kumar, S., \& Dileep Kumar, B. S. (2014). Plant growth-promoting rhizobacterial strainmediated induced systemic resistance in tea (Camellia sinensis (L) O. Kuntze) through defense-related enzymes against brown root rot and charcoal stump rot. Applied Biochemical Biotechnology 174, 506-521.

Ramkumar, S., Suresh-kumar, P., Sudhakar, G., Anitha, J., Geetha, S., Mohankumar, P., Kanniappan, V., \& Gopalakrishnan, M. (2015). Biochemical and molecular analysis of Camellia sinensis (L.) O. Kuntze tea from the selected P/11/15 clone. Journal of Genetic Engineering and Biotechnology. 14, 69-75.

Sanderson, G. W. (1966). 5-Dehydroshikimate reductase in the tea plant (Camellia sinensis L.) properties and distribution. Biochemical Journal, 98, 248-252.

Saravanakumar, D., Vijayakumar, C., Kumar, N., \& Samiyappan, R. (2007). PGPR-induced defense responses in the tea plant against blister blight disease. Crop Protection, 26(4), 556-565. 
Ertürk et al., Effects of Different Biological Fertilizers Formulated With Multiple Bacteria and Carriers in Pazar 20 Tea Clones on Leaf Enzyme Activity

Smith, M., Hopkinson, D. A., \& Harris, H. (1971). Developmental changes and polymorphism in human alcohol dehydrogenase. Annals of Human Genetics, 34, 251-271.

Weatherburn, M. W. (1967). Phenol- hypochlorite reaction for determination of ammonia. Analytical Chemistry, 39, 971-974. 